\title{
OPEN Overexpression of ZmWRKY65 transcription factor from maize confers stress resistances in transgenic Arabidopsis
}

Tong Huo ${ }^{1,4}$, Chang-Tao Wang ${ }^{1,4}$, Tai-Fei Yu ${ }^{2,4}$, Da-Ming Wang ${ }^{3}$, Meng Li ${ }^{1}$, Dan Zhao ${ }^{1}$,

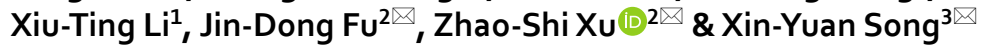

Plant-specific WRKY transcription factors play important roles in regulating the expression of defenseresponsive genes against pathogen attack. A multiple stress-responsive WRKY gene, ZmWRKY65, was identified in maize by screening salicylic acid (SA)-induced de novo transcriptomic sequences. The ZmWRKY65 protein was localized in the nucleus of mesophyll protoplasts. The analysis of the ZmWRKY65 promoter sequence indicated that it contains several stress-related transcriptional regulatory elements. Many environmental factors affecting the transcription of ZmWRKY65 gene, such as drought, salinity, high temperature and low temperature stress. Moreover, the transcription of $Z m W R K Y 65$ gene was also affected by the induction of defense related plant hormones such as $S A$ and exogenous ABA. The results of seed germination and stomatal aperture assays indicated that transgenic Arabidopsis plants exhibit enhanced sensitivity to ABA and high concentrations of SA. Overexpression of $Z m W R K Y 65$ improved tolerance to both pathogen attack and abiotic stress in transgenic Arabidopsis plants and activated several stress-related genes such as RD29A, ERD10, and $S T Z$ as well as pathogenesis-related $(P R)$ genes such as $P R 1, P R 2$ and $P R 5$; these genes are involved in resistance to abiotic and biotic stresses in Arabidopsis. Together, this evidence implies that the ZmWRKY65 gene is involved in multiple stress signal transduction pathways.

Plants are incapable of long-distance migration and therefore must respond appropriately to ever-changing environmental challenges. Numerous environmental factors, including abiotic and biotic stresses, influence plant development ${ }^{1,2}$. Among them, pathogen attack is one of the most limiting factors that severely threaten crop productivity and quality ${ }^{3}$. The plant innate immune system is composed of two interconnected branches. The first branch involves pathogen-associated molecular pattern (PAMP)-triggered immunity (PTI), which is recognized by plant receptors via a mitogen-activated protein kinase (MAPK) signaling cascade ${ }^{4,5}$. The second branch involves effector-triggered immunity (ETI); ETI is an accelerated defense response and is recognized by plant resistance (R) proteins ${ }^{5}$. R gene-activated ETI involves a complex defense program, including the production of both reactive oxygen species (ROS) and salicylic acid (SA), rapid programmed cell death (hypersensitive responses (HRs)), and the induction of many host genes, including pathogenesis-related (PR) genes ${ }^{5}$. PTI- and ETI-mediated defense responses in plants are modulated mainly by three signaling hormone molecules: SA, jasmonic acid (JA), and ethylene (ET) ${ }^{6}$. Both synergistic and antagonistic interactions occur between SA and JA/ ET signaling pathways during the progression of plant immune responses ${ }^{1,7}$. This apparent discrepancy reflects the complexity of plant defense mechanisms ${ }^{8}$.

The transcriptional regulation of defense-related gene expression is central to the induction of disease resistance in higher plants ${ }^{9}$. Several families of transcription factors involved in the transcriptional regulation of plant defense genes have been identified, including those consisting of ET-responsive factors (ERFs), Myb-like proteins, bZIP proteins, or WRKY proteins ${ }^{1,2,10}$. Among these families, the WRKY family is one of the largest transcription

\footnotetext{
${ }^{1}$ Beijing Advanced Innovation Center for Food Nutrition and Human Health/Beijing Key Lab of Plant Resource Research and Development, Institute of Cosmetic Regulatory Science, Beijing Technology and Business University, Beijing 100048, China. ${ }^{2}$ Institute of Crop Science, Chinese Academy of Agricultural Sciences (CAAS)/National Key Facility for Crop Gene Resources and Genetic Improvement, Key Laboratory of Biology and Genetic Improvement of Triticeae Crops, Ministry of Agriculture, Beijing 100081, China. ${ }^{3}$ Agro-Biotechnology Research Institute, Jilin Academy of Agricultural Sciences, Changchun 130033, China. ${ }^{4}$ These authors contributed equally: Tong Huo, Chang-Tao Wang and Tai-FeiYu. ${ }^{\circledR}$ email: fujindong@caas.cn; xuzhaoshi@caas.cn; songxinyuan1980@163.com
} 
A

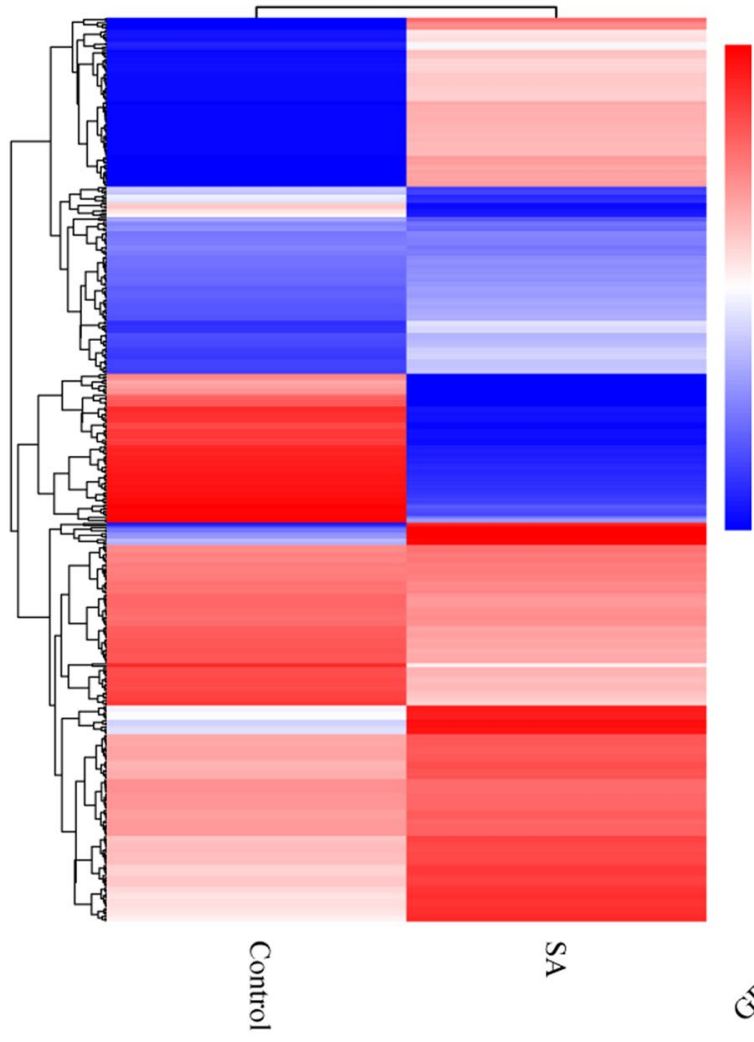

B

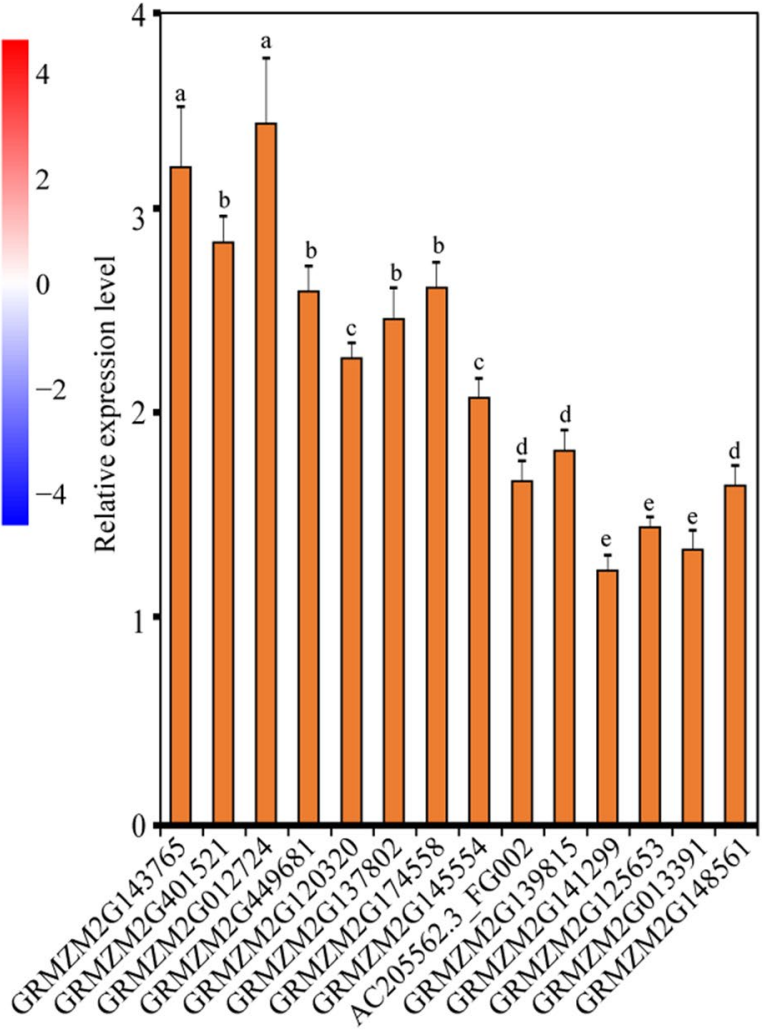

Figure 1. De novo transcriptomic sequence analyses of maize under SA stresses. (A) The cluster analyses of differential expression genes under SA treatments. (B) the transcription levels of the 14 WRKY transcription factors under SA treatments. Vertical bars indicate \pm SE of three replicates.

regulatory families among plants. WRKY proteins are characterized by their conserved DNA-binding WRKY domains, which consist of a highly conserved WRKYGQK stretch at the $\mathrm{N}$-terminus and a zinc-finger motif $\left(\mathrm{C}-\mathrm{X}_{4-5}-\mathrm{C}-\mathrm{X}_{22-23}-\mathrm{H}-\mathrm{X}_{1}-\mathrm{H}\right.$ or $\left.\mathrm{C}-\mathrm{X}_{7}-\mathrm{C}-\mathrm{X}_{23}-\mathrm{H}-\mathrm{X}_{1}-\mathrm{C}\right)$ at the $\mathrm{C}$-terminus ${ }^{11,12}$. WRKY transcription factors are divided into three groups based on the number of WRKY domains and zinc-finger motifs ${ }^{3,11}$. Group I proteins have two WRKY domains, each containing a $\mathrm{C}_{2} \mathrm{H}_{2}$ zinc-finger motif; group II proteins embody one WRKY domain and $\mathrm{a} \mathrm{C}_{2} \mathrm{H}_{2}$ motif; and group III proteins contain a single WRKY domain and a $\mathrm{C}_{2} \mathrm{H}_{2}$ motif ${ }^{11,13}$.

Pathogen treatments can lead to the selective up-regulation of several WRKYs ${ }^{14-17}$. WRKYs bind specifically to $\mathrm{W}$-box sequences containing an invariant TGACC/T core sequence; these $\mathrm{W}$-boxes are in the promoters of many plant defense-related genes ${ }^{18-20}$. Accordingly, WRKYs are involved in defense responses. 49 WRKY genes in Arabidopsis are induced by SA or pathogens ${ }^{21}$. And Magnaporthe grisea induced 15 WRKY genes in rice ${ }^{22}$. At least 13 Oryza sativa WRKY (OsWRKY) genes are known to positively regulate rice resistance against pathogens such as M. oryzae, Rhizoctonia solani and Xanthomonas oryzae pv. oryzae (Xoo) $)^{3,23-26}$. The transcriptional regulatory mechanisms of WRKYs during the induction of the defense response have been well studied ${ }^{16,27}$. Plant MAPK cascades function via WRKYs to regulate downstream gene expression during the defense response $\mathrm{e}^{28}$. By releasing AtWRKY33 in the nucleus, AtMPK4 regulates the expression of defense genes such as PAD $3^{29}$. The AtWRKY33 protein is also phosphorylated by AtMPK3/AtMPK $6^{30}$. OsWRKY53 functions downstream of the wound-responsive OsMKK4-OsMPK1 cascade to improve tolerance to rice blast fungus ${ }^{31}$. In Nicotiana benthamiana, WRKY8 plays a role in defense response and is phosphorylated by SIPK, NTF4, and WIPK ${ }^{32}$.

Maize (Zea mays L.) is widely cultivated in temperate and tropical zone of the world. In these regions, the environmental conditions are diminishing, especially due to pathogen attack, which severely affect grains development and productivity. WRKY genes mediate abiotic and biotic stress responses in plants, but little information about the mechanisms of WRKYs in maize ${ }^{33}$. ZmWRKY106 and ZmWRKY40 were found to improve the tolerance to drought and high-temperature stress ${ }^{34,35}$. In the present study, we identified a multiple stress-responsive WRKY gene, ZmWRKY65, by screening a SA-induced de novo transcriptomic sequence of maize. Overexpression of ZmWRKY65 in transgenic Arabidopsis plants improved tolerance to both pathogen attack and drought.

\section{Results}

Drought- and SA-induced de novo transcriptomic sequence analyses of maize. De novo transcriptomic sequence analyses (De novo transcriptome sequencing of maize SRP144573, https://www.ncbi.nlm. nih.gov/search/all/?term=SRP144573)34 of maize showed, the transcription levels of many genes had been changed under stress treatment (Fig. 1A). Transcription factors became the prime candidates to study, played 
important roles in regulating the expression of stress-related genes in plants. The results showed a large number of transcription factor genes existed differential expressions before or after the treatment. WRKY transcription factors were reported to response to biotic and abiotic stresses among these transcription factors ${ }^{36}$. Analysis found that 14 WRKY transcription factors were induced to up-regulated by drought ${ }^{34}$ and SA treatments (Fig. 1B). The 14 ZmWRKY gene family members in Fig. 1B were renamed in order from GRMZM2G143765 to GRMZM2G148561 ${ }^{35}$. Among these 14 WRKY transcription factor, ZmWRKY65, had the highest expressions than others under drought and SA treatments and was chosen for further study. The result of the KEGG pathway database showed the 'signal transduction of plant hormone' and 'interaction between plant and pathogen' pathway enriched the most DEGs under drought and SA treatments, respectively (Figure S1A and S1C). The result of Gene Ontology classification showed the 60 predominant GO classifications were presented in Figure S1B and S1D. Signaling and response to biotic stimulus in Figure S1B and S1D were enriched and among the predominantly enriched groups.

Phylogenetic analysis and domain organization of the putative maize WRKY65. ZmWRKY65, a putative WRKY member selected from the drought- and SA-treated maize de novo transcriptomic data, contains a 1548-bp open reading frame (ORF) that encoded 516 amino acids and contains a predicted WRKYGQK domain coupled with an N-terminal coiled-coil domain (amino acids 102-142) as well as a zinc-finger motif $\left(\mathrm{C}-\mathrm{X}_{5}-\mathrm{C}-\mathrm{X}_{23}-\mathrm{H}-\mathrm{X}_{1}-\mathrm{H}\right)$. WRKY protein sequences of fifteen available high homology from various species and the 14 maize WRKY transcription factors from drought- and SA-induced de novo transcriptomic sequence were downloaded from the Phytozome 12.1 public database (https://phytozome.jgi.doe.gov/pz/portal.html), and the program MEGA 5.1 was used to establish a neighbor-joining phylogenetic tree (Fig. 2A). The highly homologous sequences with ZmWRKY65 from the phylogenetic tree and 14 maize WRKY transcription factor sequences were selected for further analysis, and the results of multiple amino acid sequence alignments also showed that Arabidopsis AtWRKY3, rice OsWRKY96, millet SiWRKY3 and soybean WRKY33 shared the highest genetic similarity with ZmWRKY65, indicating possible functional similarity among them (Fig. 2B).

Analysis of the ZmWRKY65 promoter. To gain insight into the mechanism responsible for the transcriptional regulation of $Z m W R K Y 65$, we isolated a 2.0-kb promoter region upstream of the ZmWRKY65 ATG start codon. According to the Plant Cis-acting Elements database (http://www.dna.affrc.go.jp/PLACE/), several stress response-related cis-acting elements are present in the promoter region (Table S1). Several regulatory elements responding to drought, abscisic acid (ABA), cold and salt were also recognized, including ABA-responsive element (ABRE PyACGTGG/TC) MYB-responsive element (MYB TGGTTAG) MYC-responsive element (MYC CACATG) dehydration- responsive element (DRE CCGAC) low temperature- responsive element (LTRE CCGAC) recognition site sequences (Figure S2). Overall, the results of this analysis suggest that ZmWRKY65 probably functions in the abiotic stress response.

Subcellular localization and expression pattern analyses of ZmWRKY65. To determine the subcellular localization of ZmWRKY65, using the PEG-mediated method, we transformed ZmWRKY65-GFP constructs under the control of the CaMV 35S promoter into wheat mesophyll protoplasts. The subcellular localization of green fluorescent protein (GFP) expression in the wheat mesophyll protoplasts was subsequently observed. At the same time, the hGFP reporter construct was transformed into wheat mesophyll protoplasts, which served as controls. Relative to the hGFP reporter construct, the ZmWRKY65::hGFP fusion protein was localized in the nucleus (Fig. 3A). The nucleus, cytoplasm and cell membrane proteins of wheat mesophyll protoplasts were extracted for western blot analysis. The result showed the ZmWRKY65-GFP signal were detected in nucleus, however, the control GFP were detected in nucleus, cytoplasm and cell membrane (Figure S3).

To further investigate the response of $Z m W R K Y 65$ to abiotic stresses, we performed quantitative real-time PCR (qRT-PCR) using RNA isolated from stress-treated maize plants. The results showed that ZmWRKY65 could be induced by drought, $\mathrm{NaCl}$, high temperature, low temperature, SA and ABA (Fig. 3B). ZmWRKY65 rapidly responded to drought and peaked (more than tenfold) at $1 \mathrm{~h}$ after treatment. Under salt stress, the transcription level of ZmWRKY65 increased gradually, peaked at a level 8.87-fold greater than that of the control at $2 \mathrm{~h}$ and then rapidly decreased to a level similar to that of the control. Under high-temperature stress, ZmWRKY65 transcript levels were up-regulated and peaked at 4.98 -fold greater levels at $12 \mathrm{~h}$. In response to exogenous ABA treatment, $\mathrm{ZmWRKY65}$ transcript levels were up-regulated and peaked at 3.38-fold greater levels at $12 \mathrm{~h}$.

Effects of ABA and SA on the germination of transgenic Arabidopsis. To determine the sensitivity of transgenic ZmWRKY65 Arabidopsis plants to ABA and SA, germination assays were carried out. Three T3 homozygous lines that exhibit relatively high transcriptional levels of ZmWRKY65 in transgenic Arabidopsis were selected for further analysis. The wild-type (WT) and transgenic Arabidopsis line seeds were placed on $1 / 2 \mathrm{MS}$ medium supplemented with various concentrations of ABA and SA. The results showed that the transgenic ZmWRKY65 Arabidopsis lines were more sensitive than WT lines were to ABA and high concentrations of SA (Fig. 4A). In response to treatment with exogenous ABA and high concentrations of SA, the growth of WT and transgenic Arabidopsis lines was inhibited, and the transgenic Arabidopsis lines had lower germination rates than did the WT lines (Fig. 4B, 4C, 4D and 4E). Furthermore, at $72 \mathrm{~h}$ after high concentrations of ABA and SA treatment, approximately $70 \%$ of the transgenic Arabidopsis seeds germinated. At that point, however, approximately $90 \%$ of the WT seeds germinated (Fig. 4).

ZmWRKY65 improves stress tolerance in transgenic Arabidopsis. To verify the tolerance of transgenic Arabidopsis plants to abiotic stresses, drought, salt, low temperature and high temperature were imposed 
A

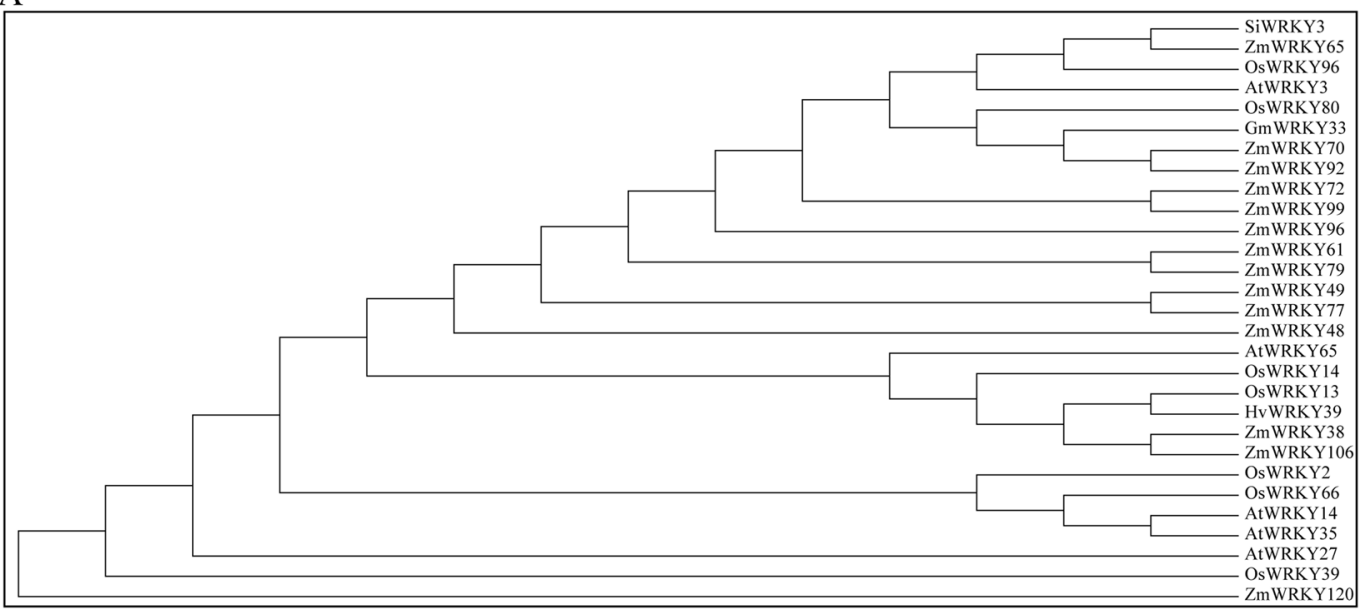

B

GmWRKY33 SVQFNST ........FAPKS IREORRSEDGYNWRKYGEKOVKGSENPRSYYKCTHPS ...CPTKKKVERSLEG. HITEIVYKGSHNH AtWRKY3 ETSOGORETSE ISVFEHRSOPONADKPADDGYNWRKYGOKOVKGSDEPRSYYKCT HPA..... CPVKKKVERSLDG. OVTE ITYKGOHNH OsWRKY96 PAEASQR ......... YQVNAP. . VDKPADDGYNWRKYGQKVVKGSDCPRSYYKCTHPN . . . CPVKKKVEHAEDG. QISEIIYKGKHNH OSWRKY96 PAEASQR.......... Y QVNAP..VDKPADDGYNWRKYGQKVVKGSDCRSYYKCTHPN . . . CPVKKKVEHAEDG. QISEIIYKGKHNH ZmWRKY48 HARFRRAP..$\ldots \ldots \ldots \ldots \ldots$ AAAAKPI GMTETEAALPPASGRQAVAVEPAQKTEPA. . QKTALTLDFAKPAPAPAVSATSTSELS

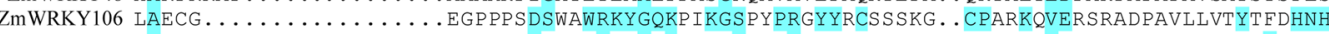
ZmWRKY79 TGCWGPR . . . . . . . . . TSSLADGKDEAKTLEARLTQVSEENRR $\ldots \ldots \ldots \ldots$ LTEIIAYMYASQVAARRSPDGRKRS ZmWRKY38 LAECGDR . ......... PRGASGEGPPPSDSWAWRKYGQKPIKGSPYPRGYYRCSSSKG . CPARKQVERSHADPTALLVTYTFEHNH ZmWRKY77 KKRHEVRVG........ SAGGGGGDHPADDGYSWRKYGQKE ILGAKHPRGYYRCTHKSS QGCAATKQVQRTDEDPAFFDVVYLGDHTC ZmWRKY49 PAGASPKKRK . ....ATARWTSQQVRVSADDGHSWRKYGQKDILGARHPRAYYRCTHRNSQNCLATKQVQRADDHPALFDVVYHGEHTC

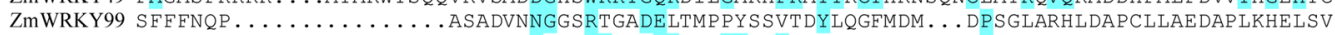

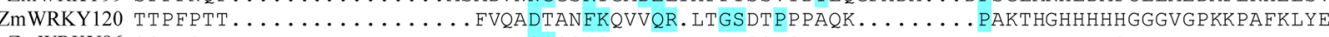

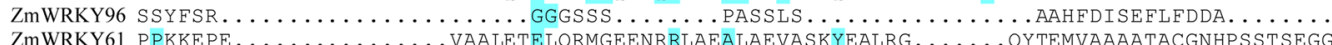
ZmWRKY92 AAVPSSN . . . ..... RASGGGNGNTKLEDGYNWRKYGQKOVKGSENPRSYYKCTYHS . . . CSMKKKVERALADGRI TQIVYKGAHNH ZmWRKY70 SAVPS SN . . . ............. KASGGSGGSTKLEDGYNWRKYGOKOVKGSENPRSYYKCTYHS . . . CSMKKKVVRSLADGRVTOTVYKGAHNH

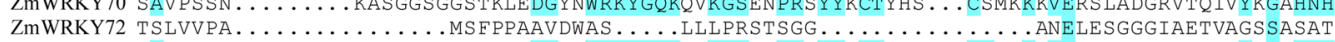

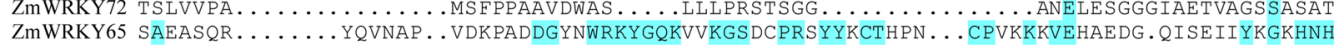
GmWRKY33 PKPHGRKNGSQS. . IHQTSSPCTNSGIS . .... DQSVGDEDLEQTSQTSYSGGGDDDLGN . . . . ....EAKRWKGENENDGYSYSS AtWRKY3 ELPQKRGNNNGSC. KSSDIANQEQT SNSSLNKSKRDQETSQVTTTEQMSEASDSEEVGNAETSVGERHEDEPDPKRRNTEVRVSEPVA OsWRKY96 QRP PNKRAKDGSS. SAADQNEQSNDTVSGLSGIKRDQEA. I YGMSEQLSGLSEGDDMDDGESRPHEADDKESDSKKRNIQI $\ldots . .$.

SiWRKY3 QRP PNKRAKDGNS. SAADQNEQSNDTTSGLSGAKRDQDA. IYGMSEQVSGLSDGDDMDDGESRPHEVDDADNESKRRNIQI $\ldots \ldots$ ZmWRKY48 SVTAGGEASKGCSLAAVSSGKPPLPKRK . . .... LPPCAAAVPHHHQHQAHHPHPAERCHCSSKKKRARHGMLSRRTVRVP $\ldots .$. ZmWRKY106 EAPRPKSS . . CCHQQG . . . RPPAPKPD . . . . . . . . EPVAEEQEDELGPEHE . . . . . . . . PEDEQEPEQKV . . . . .

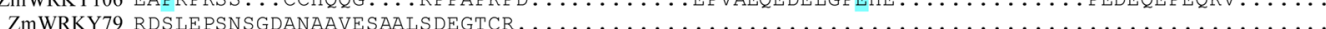

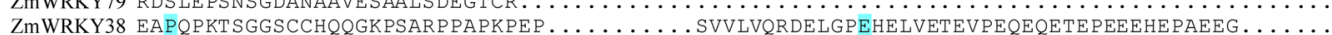
ZmWRKY77 VQSQRAAATAGRQAAADAQAPEYDAN $\ldots \ldots \ldots \ldots \ldots$ IMVKTEGPALEPEQQ $\ldots \ldots \ldots \ldots \ldots \ldots$ ZmWRKY49 RPAAAGGGSKRAQQHNPHAQAALQGLAAR $\ldots \ldots \ldots \ldots$ LTVATTTTDNAAGLP $\ldots \ldots \ldots \ldots \ldots \ldots \ldots \ldots \ldots$ ZmWRKY99 DVSYDSQGTSGAPGDGAAAMHTPNSSVS $\ldots \ldots \ldots$ LSSSDREGEGQLRRCRKGRPKAEDDAEGDEKDQEDGENSTKANRS $\ldots \ldots$

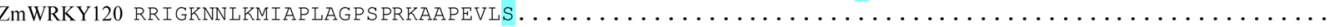

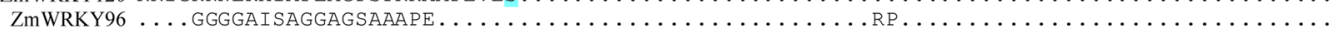

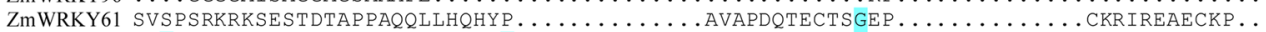

ZmWRKY92 PKPLSTRRNSSGGGAAAEEIQAGNSSLSAAAAAGCTGPEHSG. ATAENSSVTFGDDEAENGSQRSDGDEPDAKRWKQEDGENEGSSAG ZmWRKY70 PKPLSTRRNSSGGVAAAEEQAANNSSIS......GCGGPEHSGGATAENSSVT FGDDEAENGSQRSGGDEPDAKRWKAEDGENEGCSGA

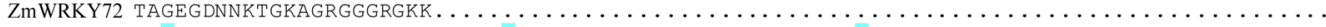

ZmWRKY65 QRPPNKRAKDGNS. SAADHNEQSNDTASGLSAAKRDQDN. IYGMSEQASGLSDGDDMDDGESRPHEVDDADNESKRRNIHI ......

GmWRKY33 AGSRTVKEPKVVVQTTSEIDILDDGYRWRKYGQKVVKGNPNPRSYYKCVAPG. CPVRKHVERASHDMKAVITTYEGKHIHDVPLGRGN AtWRKY3 SSHRTVTEPRIIVQTTSEVDLLDDGYRWRKYGQKVVKGNPY PRSYYKCTTPD. CGVRKHVERAATDPKAVVTTYEGKHNHDVPAARTS OsWRKY96 SSQRTSAEAKIIVQTT SEVDLLDDGYRWRKYGQKVVKGNPHPRSYYKCTYAG. CNVRKHIERASSDPRAVITTYEGKHNHEPPVGRGN

SiWRKY3 SSORTLSEPKIIVOTTSEVDLLDDGYRWRKYGOKVVKGNPHPRSYYKCTFAG. CNVRKHIERASSDPKAVITTYEGKHNHEPPVGRGS ZmWRKY48 AAAAAAGSQP PHPHAPASSDI PADDYSWRKYGQKPIKGSPY PRGYYRCSSAKGCPARKHVERAADDPATLVVTYEGDHRHDAAAGHAP ZmWRKY106 VPGLAGPETAPATAT LAPVAEEDESEDLGWFDQ....... YPTWHRSAL YAP. L LPPEEWERE LQGEDALFAGLGEL PECAVVFGRRR ZmWRKY79 ..RIKLTRVCTKIDPS DTTLTVKDGYQWRKYGQKVTRDNPS PRAYFRCAYAPSCPVKKKVQRSAEDSAMLVATYEGEHNHPSPTRAGE ZmWRKY38 VPCLAGPEAA.ATLTVAPAAEEDESEDFGWFDQ ....... YPTWHRSALYAP. LLPPEEWERE LQGEDALFAGLGELPECAVVFGRRR ZmWRKY77 ...FLFSSTPACLVPERSPFSAPSTSENWGVSPATS. DSNHVVSFPPFEVAAAAAAQFEFEEVMSAIDRADGEFLEDLDIYVSSFLA. ZmWRKY 49 .... PMTPESCPVRGASSPWSLASPVGSDFNGCLHQGISPCPVPGYRDWTSD.VDLQEVVSSAFAAVSSVAPLPVPDDEFMPLECVEY ZmWRKY99 KKKAEKROPRVAFLTKSEVDHLE.DGYRWRKYGQKAVKNSPYPRSYYRCTAPK. CGVKKRVERSYQDPSTVVTTYEGOHTHHSPASFRA ZmWRKY99 KKKAEKRQPRVAFLTKSEVDHLEDGYRWRKYGQKAVKNSPYRSYYRCTAPK.CGVKRVER

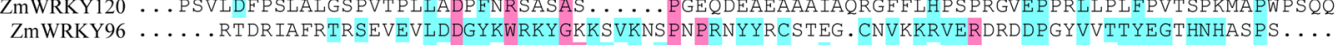
ZmWRKY61 …RVSKLHVHADPADLS LVVKDGY QWRKYGQKVTKDNPC PRAY FRCS FAPACPVKKKVQRSADDPT ILVATYEGDHNHGQP P PQA ZmWRKY92 AGGKPVREPRLVVQTLSDIDI LDDGERWRKYGQKVVKGNPNPRSYYKCTTAG. CPVRKHVERASHDKRAVITTYEGKHNHDVPVGRGA ZmWRKY70 GGGKPVREPRLVVQTLSDI DI LDDGERWRKYGQKVVKGNPNPRSYYKCTTAG. CPVRKHVERACHDARAVITTYEGKHNHDVPVGRGA ZmWRKY72 …KA.SRPRFAFQTRSEDDVLDDGYRWRKYGQKAVKNSAFPRSYYRCTHHT . CEVKKQVQRLAKDTS IVVTTYEGVHNHPCEK .... ZmWRKY65 SSQRTLSEPKIIVQTT SEVDLLDDGYRWRKYGQKVVKGNPHPRSYYKCTFAG . CNVRKH I ERC SSDPKAVITTYEGKHNHEPPVGRGG

Figure 2. Analyses of sequence alignments and phylogenetic tree. (A) Phylogenetic analysis of ZmWRKY65 in relation to closely related WRKY proteins. (B) Alignment of the putative amino acid sequence of ZmWRKY65 with sequences from Arabidopsis, rice, millet, barley and soybean. 


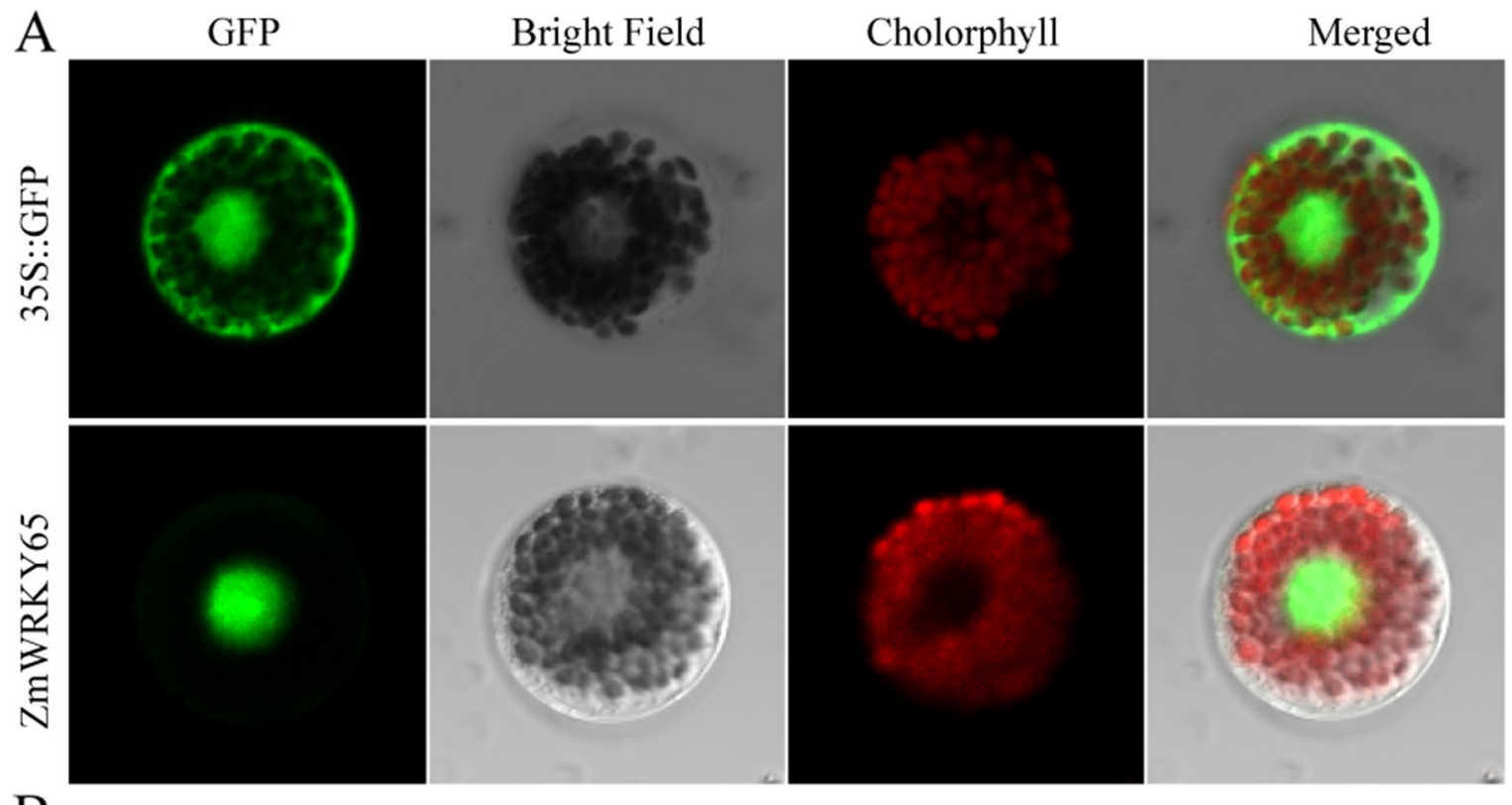

B
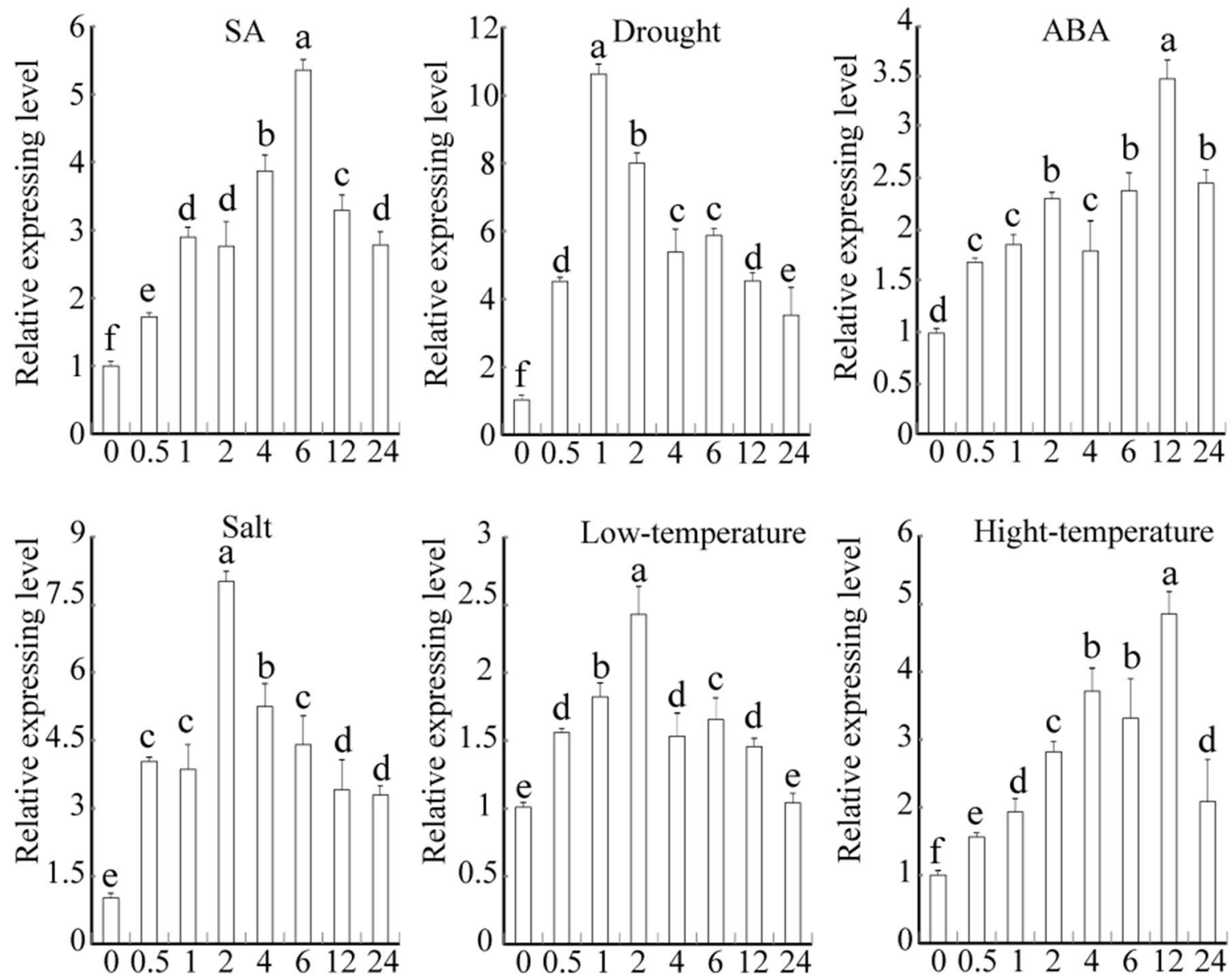

Figure 3. Molecular characteristic analysis of $Z m W R K Y 65$ gene. (A) Green fluorescent signals of control (GFP) and ZmWRKY65-GFP were detected in wheat epidermal cells with a laser confocal scanning microscope. (B) The expression patterns of the ZmWRKY65 gene under different stress treatments. ZmWRKY65 up-regulation was induced by hormones (ABA and SA) and responded to drought, salt, high-temperature and lowtemperature stresses. The results shown are averages of three replicates. Vertical bars indicate \pm SE of three replicates. 
A

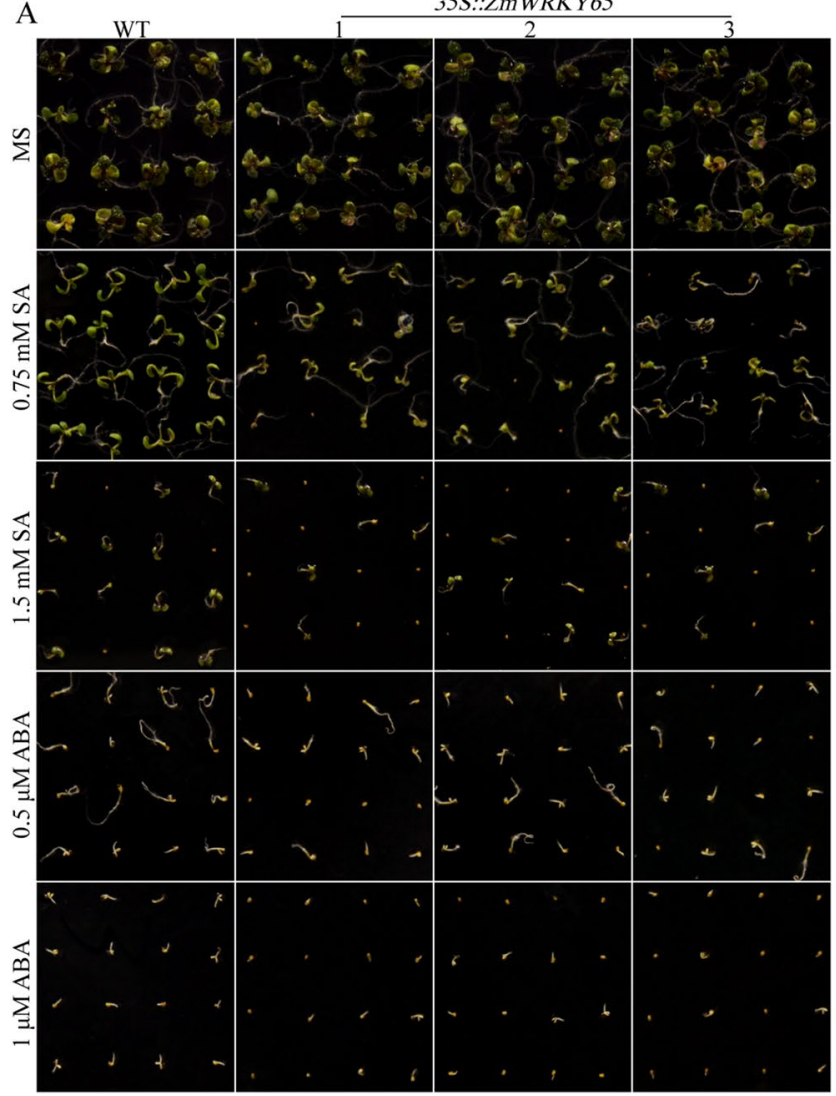

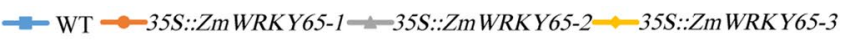

$\mathrm{B}$

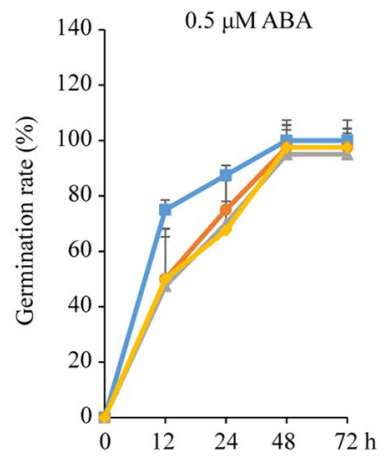

D

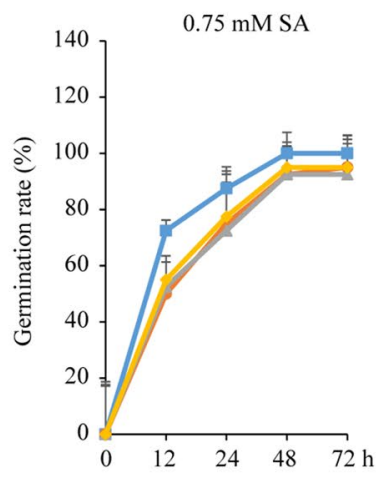

$\mathrm{C}$

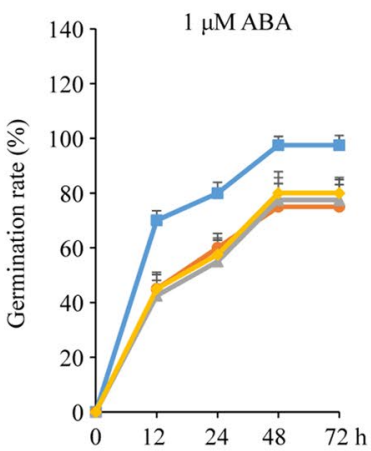

E

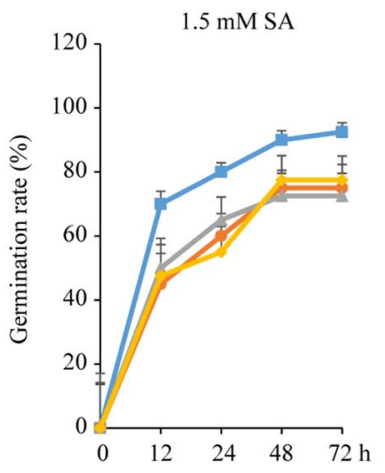

Figure 4. Germination of transgenic Arabidopsis plants and WT under different hormone treatments. (A) The germination phenotypes of WT and ZmWRKY65 transgenic Arabidopsis plants under different hormone treatments. (B) The germination rates of WT and ZmWRKY65 transgenic Arabidopsis plants under $0.5 \mu \mathrm{M}$ ABA treatment. (C) The germination rates of WT and ZmWRKY65 transgenic Arabidopsis plants under $1 \mu \mathrm{M}$ ABA treatment. (D) The germination rates of WT and transgenic ZmWRKY65 Arabidopsis plants under $0.75 \mathrm{mM} \mathrm{SA}$ treatment. (E) The germination rates of WT and ZmWRKY65 transgenic Arabidopsis plants under $1.5 \mathrm{mM} \mathrm{SA}$ treatment. The results are averages of three replicates. Vertical bars indicate \pm SE of three replicates.

on three-week-old T3 homozygous lines. Under non-stressed conditions, no differences were observed in survival rate or relative electrical conductivity between the transgenic and WT plants (Fig. 5A). However, after the stress treatments, the significant differences were observed between the transgenic and WT plants: the transgenic Arabidopsis plants had a higher survival rate (Fig. 5B, D, F, H) and a lower relative electrical conductivity (Fig. 5C, E, G, I) than did WT plants. Under the stress treatments, approximately $60 \%$ of transgenic Arabidopsis plants survived, and only approximately $15 \%$ of WT plants survived.

Effects of ABA on stomatal movement and the water loss rate. To further analyze the effects of ABA on transgenic Arabidopsis plants, stomatal aperture sizes were assayed. As shown in Fig. 6, the mean stomatal apertures of the control and transgenic Arabidopsis leaves decreased concurrently as the concentrations of ABA increased, and following treatment with exogenous ABA, the stomata of the transgenic Arabidopsis leaves closed faster than did the stomata of the control leaves. This result provides more evidence that overexpression of ZmWRKY65 in Arabidopsis improves sensitivity to ABA. This result provides more evidence that overexpression of ZmWRKY65 in Arabidopsis improves sensitivity to ABA. The transgenic Arabidopsis leaves showed lower rates of water loss during dehydration than did the control leaves (Fig. 6C). For example, at the $0.5 \mathrm{~h}$ time point of dehydration, the control Arabidopsis leaves revealed a water loss of $4.3 \%$, whereas the transgenic Arabidopsis leaves revealed a loss of $1.6 \%$ (average of the three transgenic lines); such differences in water loss between the WT and transgenic plants persisted and grew larger as time progressed. At the 6-h time point of dehydration, the control Arabidopsis leaves revealed a water loss of 39.9\%, whereas the transgenic Arabidopsis leaves revealed a loss of $28.4 \%$ (average of the three transgenic lines).

Overexpression of ZmWRKY65 improves resistance against Botrytis cinerea and Pst. DC3000 in transgenic plants. To analyze the disease resistance of transgenic Arabidopsis plants, 3-week-old seedlings of transgenic and WT Arabidopsis plants were investigated. As shown in Fig. 7A, overexpression of ZmWRKY65 in Arabidopsis improved disease resistance, and when Arabidopsis leaves (pretreated with water) were inoculated with Pst. DC3000 and B. cinerea, severe disease symptoms and extended hyphae were observed 


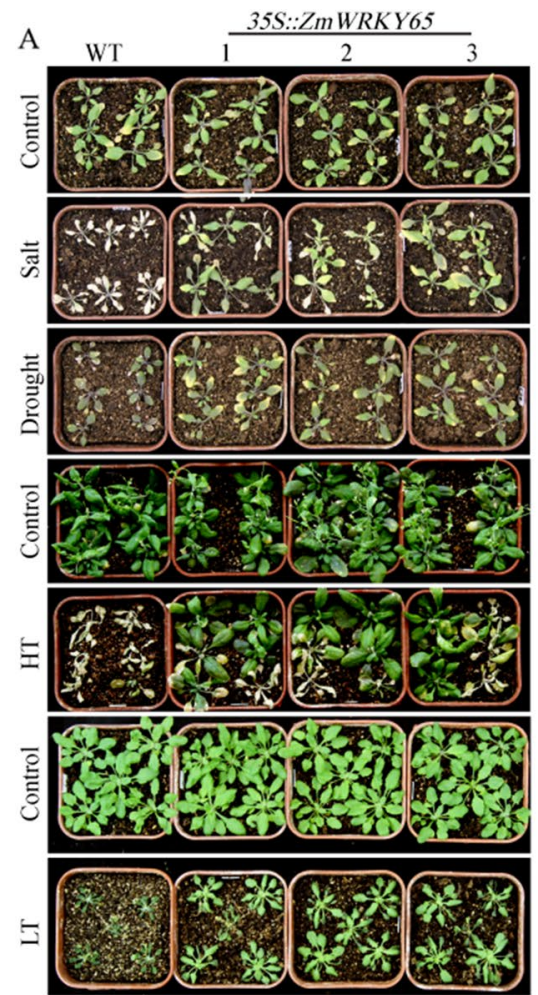

B

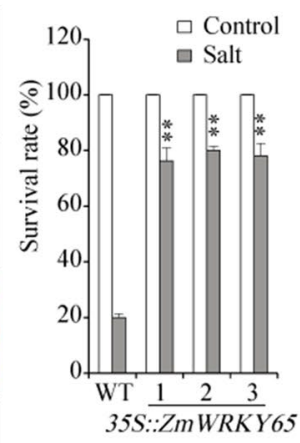

$\mathrm{F}$

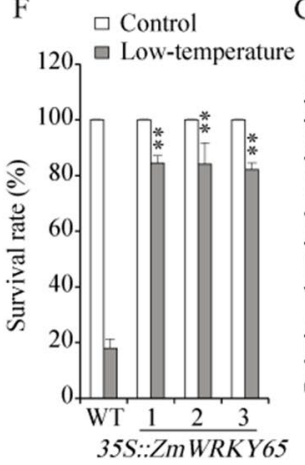

$\mathrm{C}$

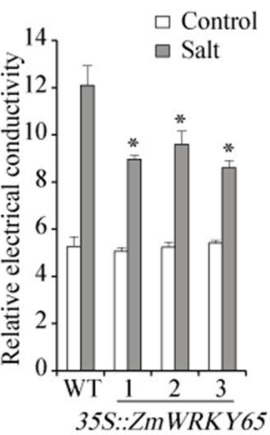

$\mathrm{G}$

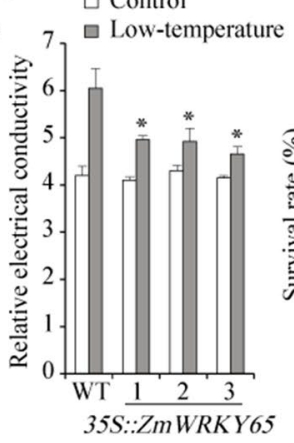

D

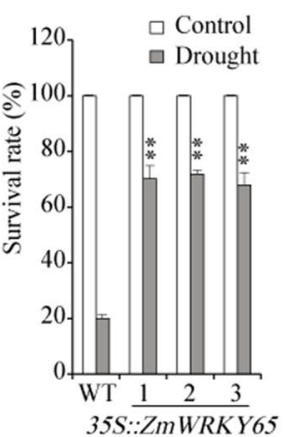

$\mathrm{H}$

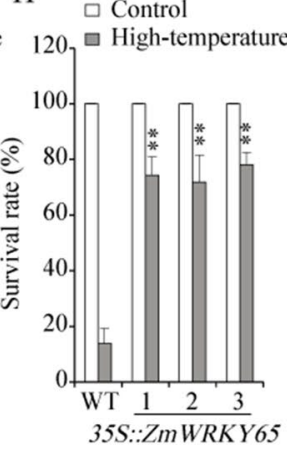

E

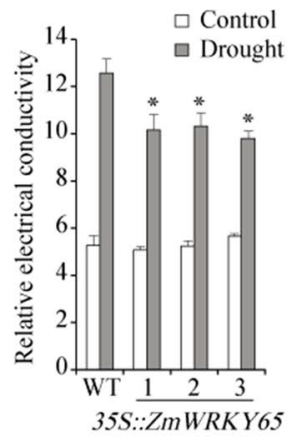

I $\square$ Control

7 High-temperature

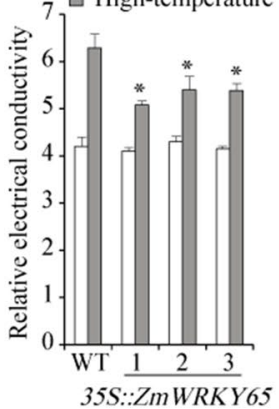

Figure 5. Stress tolerance of WT and transgenic Arabidopsis plants under different treatment conditions. (A) The phenotypes of WT and transgenic ZmWRKY65 Arabidopsis plants under different stress treatments. (B) and (C) The survival rates and relative electrical conductivities of WT and ZmWRKY65 transgenic Arabidopsis plants under salt treatments. (D) and (E) The survival rates and relative electrical conductivities of WT and ZmWRKY65 transgenic Arabidopsis plants under drought treatments. (F) and (G) The survival rates and relative electrical conductivities of WT and ZmWRKY65 transgenic Arabidopsis plants under low-temperature treatments. (H) and (I) The survival rates and relative electrical conductivities of WT and ZmWRKY65 transgenic Arabidopsis plants under high-temperature treatments. The results are averages of three replicates. Vertical bars indicate \pm SE of three replicates. ${ }^{\star},{ }^{*}$ indicate significant differences in comparison with the WT lines at $0.01<\mathrm{P}<0.05$ and $\mathrm{P}<0.01$, respectively.

3 days after inoculation with Pst. DC3000 and 8 days after inoculation with $B$. cinerea. After being inoculated with Pst. DC3000, the leaves of WT plants were wilted and dried up on the third day; however, the leaves of transgenic plants showed mild wilting (Fig. 7A). A similar phenotype was observed 8 days after inoculation with B. cinerea. The results of the statistical analysis showed that at 3 days post-infection, the bacterial titres of the three transgenic lines were significantly lower than those of the WT lines (Fig. 7B). Similarly, the results of the disease severity tests showed that $57 \%$ of the transgenic Arabidopsis plants (average of the three transgenic lines) exhibited first-degree disease symptoms at 8 days after inoculation with $B$. cinerea; however, $71 \%$ of WT plants exhibited second-degree disease symptoms, and 9\% exhibited third-degree disease symptoms (Fig. 7C). Meanwhile, the changes of SA level were monitored in transgenic Arabidopsis and WT plants. The results showed no obvious difference was observed between the WT and transgenic Arabidopsis plants under the $\mathrm{MgCl}_{2}$ treatment, but the inoculation of isolated leaves with pathogens suspension resulted in an increase in the SA level, and significantly higher SA levels were detected in the three transgenic lines compared with WT plants (Figure S4).

Overexpression of ZmWRKY65 affected the transcription of various PR- and stress-responsive genes. In order to analyze molecular mechanisms of $Z m W R K Y 65$ in different stress responses, the expression patterns of stress-related genes in transgenic Arabidopsis and WT lines were detected under normal conditions. As shown in Fig. 8, T3 homozygous transgenic ZmWRKY65 Arabidopsis plants were tested by semiquantitative PCR, and the result showed that ZmWRKY65 could overexpress in transgenic Arabidopsis (three amplified clear and repeating bands) (Fig. 8A). Meanwhile the transcripts of disease resistance PR genes such as $P R 1, P R 2$, and $P R 5$ genes were found to up-regulated in transgenic lines (Fig. 8B). In addition, overexpression of $Z m W R K Y 65$ also increased the transcription of stress related genes such as ERD10, STZ and RD29A (Fig. 8B). These results revealed that $Z m W R K Y 65$ activated the expressions of disease- and stress-responsive genes in transgenic Arabidopsis plants. 


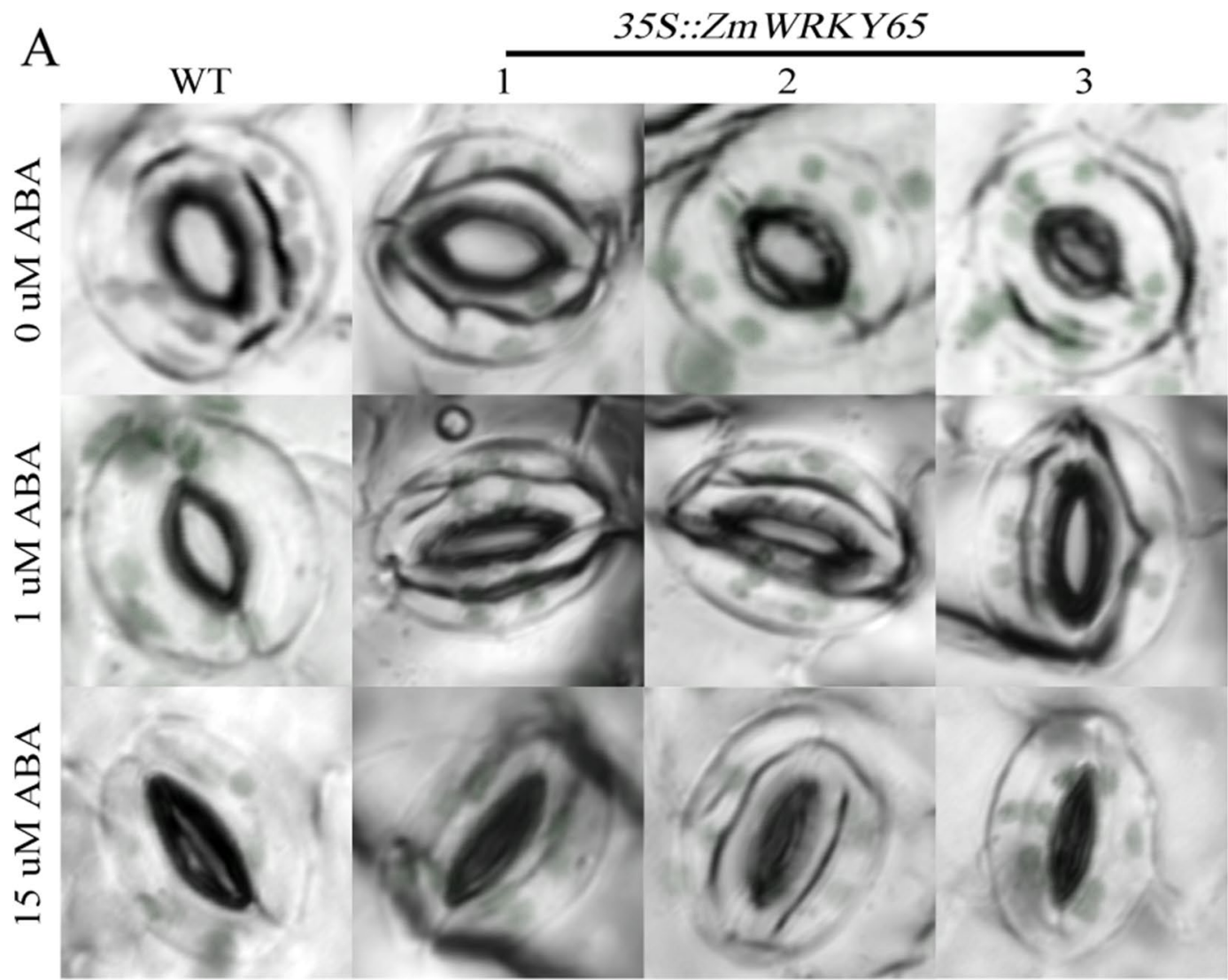

$\mathrm{B}$

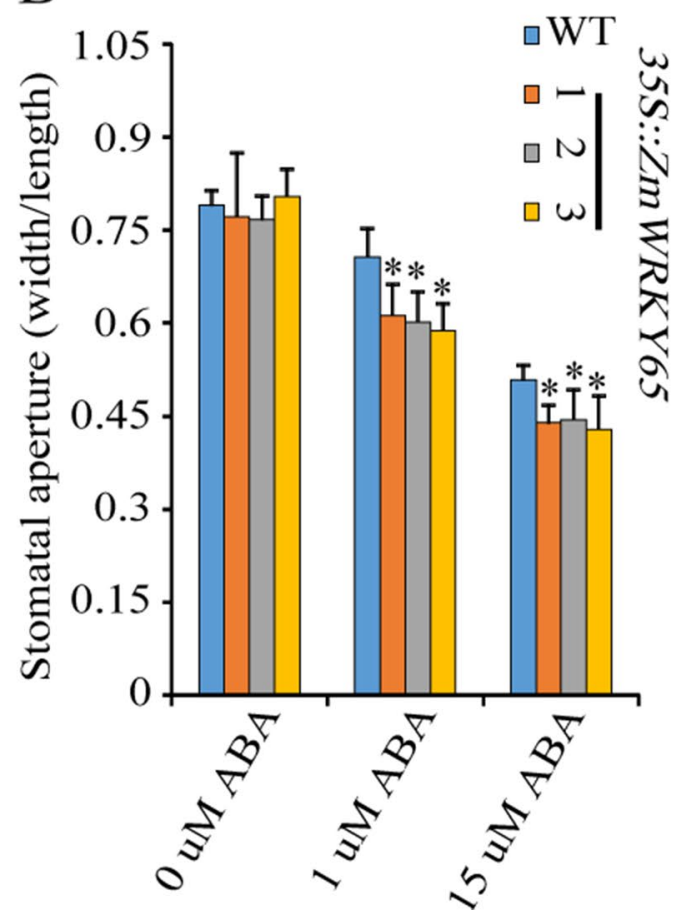

$\mathrm{C}$

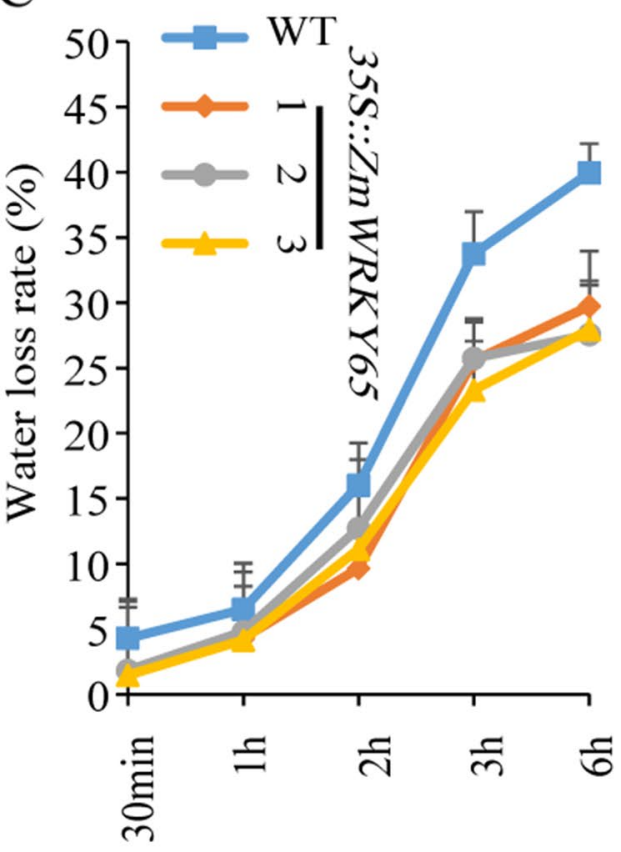

Figure 6. Effects of ABA on stomatal aperture and water loss rate. (A) The phenotypes of WT and ZmWRKY65 transgenic Arabidopsis plants under different concentrations of ABA treatment. (B) The stomatal aperture of WT and ZmWRKY65 transgenic Arabidopsis plants under different concentrations of ABA treatment. Vertical bars indicate \pm SE of three replicates. ${ }^{*}$ indicates significant differences in comparison with the WT lines at $0.01<\mathrm{P}<0.05$. (C) Water loss rate. Vertical bars indicate $\pm \mathrm{SE}$ of three replicates. 
A
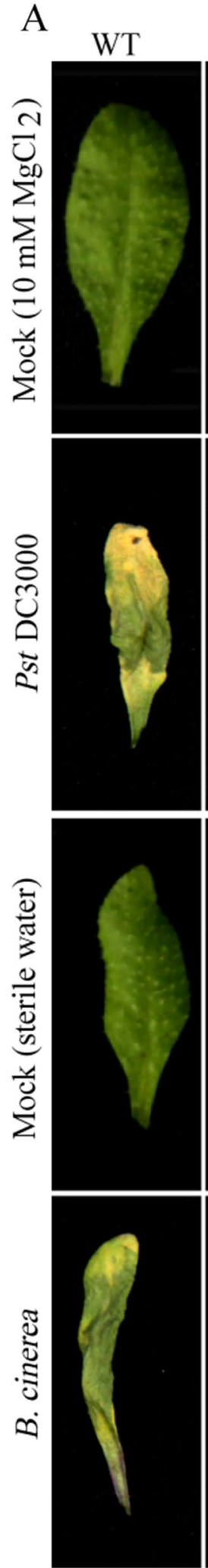

35S::ZmWRKY65
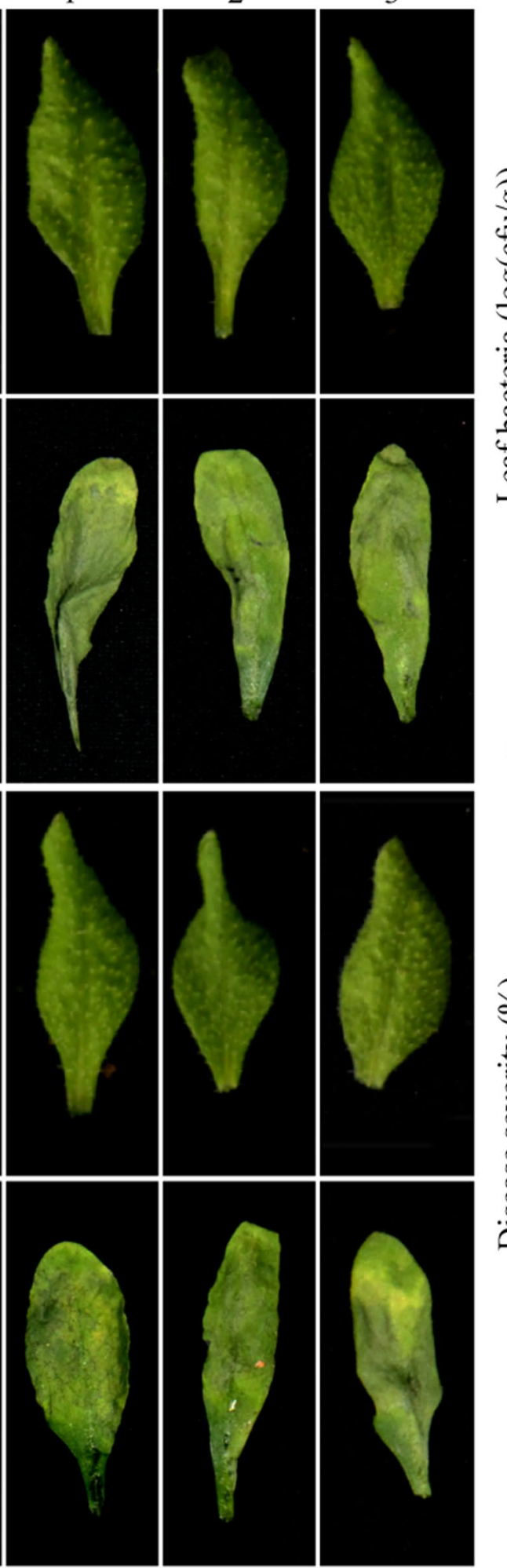

B

$\square 0$ days after inoculation

Q 3 days after inoculation

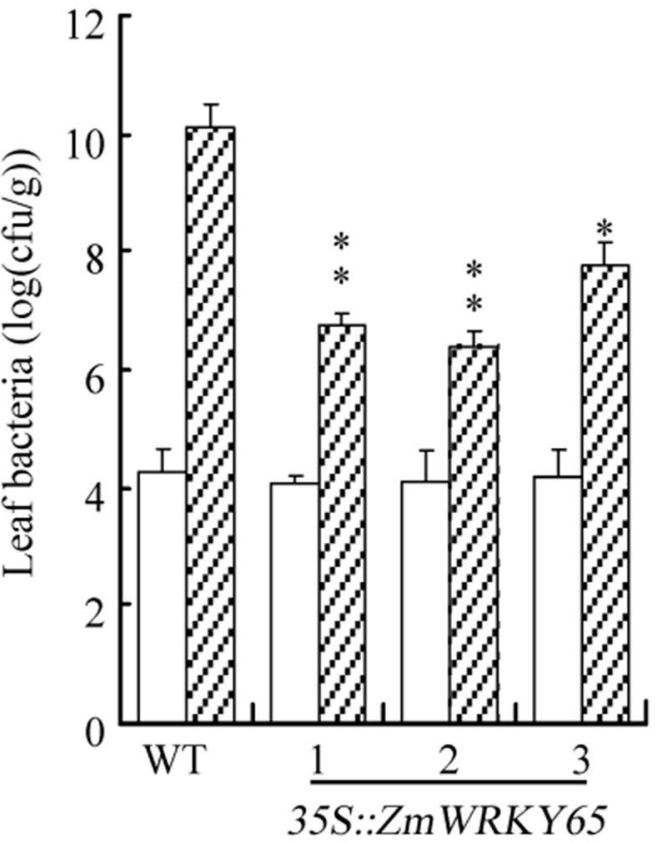

$\mathrm{C}$

Disease rating
3 田 100

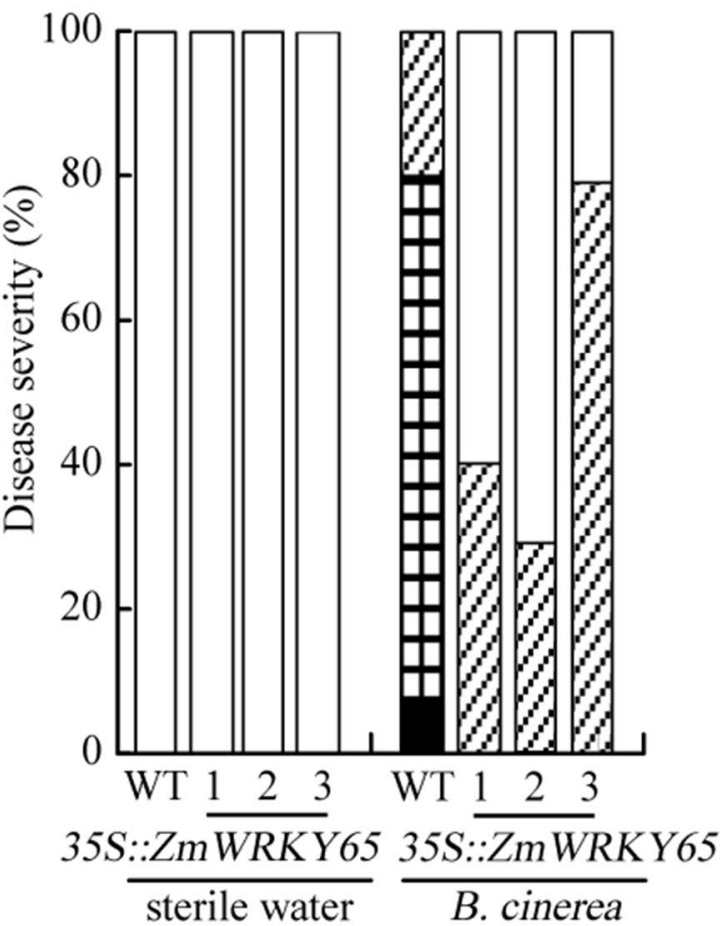

Figure 7. Fungal and bacterial pathogen tolerance of transgenic plants. (A) The phenotypes of WT and ZmWRKY65 transgenic Arabidopsis plants under bacterial and fungal treatments. (B) Bacterial pathogen (P. syringae) response of three independent transgenic Arabidopsis lines and WT. The bacterial population was investigated 3 days after the plants were inoculated with $107 \mathrm{CFU} / \mathrm{mL}$ of Pst. DC3000. The results are averages of three replicates. Vertical bars indicate \pm SE of three replicates. ${ }^{*}{ }^{* *}$ indicate significant differences in comparison with the WT lines at $0.01<\mathrm{P}<0.05$ and $\mathrm{P}<0.01$, respectively. (C) Histogram of fungal disease (B. cinerea) symptoms of three independent transgenic Arabidopsis and WT lines 8 days after the plants were inoculated with sterile water or with $2 \times 10^{5}$ conidiospores $/ \mathrm{mL} .0-3$ represent the disease rating: 0 , no infection/ necrosis; 1, 1-4 leaves showing some necrosis; 2, 5-10 leaves showing necrosis; 3 , dead plants. 
A

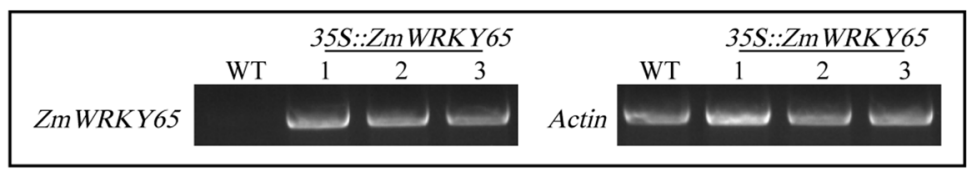

B
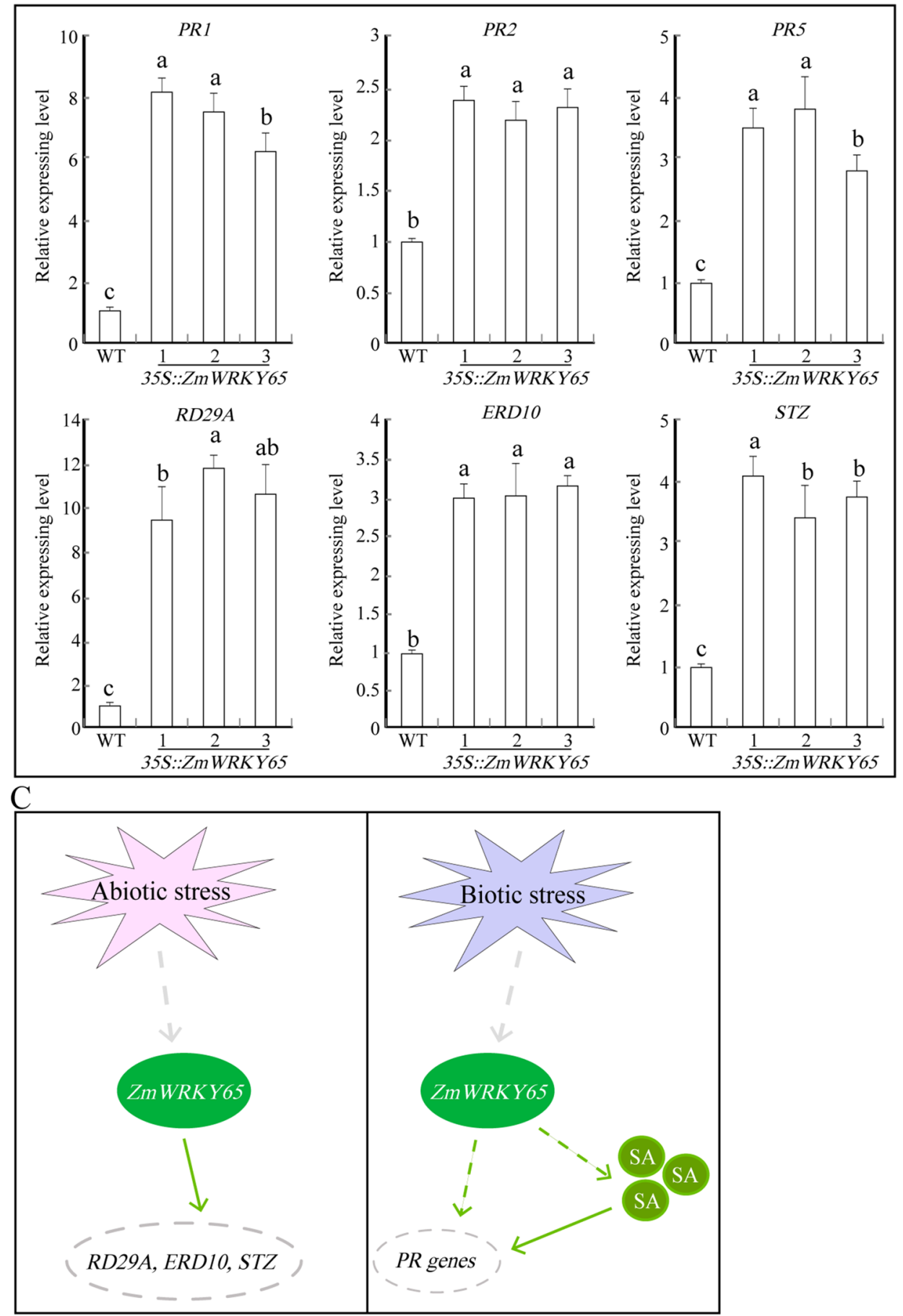

Figure 8. Expression analysis of stress-responsive genes in ZmWRKY65 transgenic Arabidopsis. (A) The transcription levels of ZmWRKY65 in transgenic Arabidopsis plants. (B) The transcription levels of stress-related genes in transgenic Arabidopsis plants. Arabidopsis Actin (ACT2) was used as an internal control. Vertical bars indicate $\pm \mathrm{SE}$ of three replicates. (C) The mode of $\mathrm{ZmWRKY} 65$ gene regulation. 


\section{Discussion}

Transcriptional regulation exert effect on the process of plant-inducible defense responses activation. Therefore, regulatory components identification and transcriptional regulatory pathways of the plant defense system establishment were high on the agenda. Thus far, multiple transcription factor families about plant defense-related genes have been identified, including ERF, Myb-like, bZIP, and WRKY families. Compared with other transcription factor families, the WRKY family has a much greater proportion of genes related to biotic stress responses, suggesting that the WRKY family fulfill a valuable function in responding to biological stress ${ }^{27}$. Most knowledge about the functions of WRKY genes in defense-related signal transduction pathways come from the analysis of dicot plants, such as Arabidopsis ${ }^{21}$, tomato ${ }^{37}$, tobacco ${ }^{38}$ and potato ${ }^{39}$; very limited information has been reported in maize ${ }^{40}$ or other monocots. It is therefore important to elucidate of the functions of WRKY proteins involved in maize defense response signaling.

Emerging evidence has highlighted the importance of WRKY transcription factors acting as positive or negative regulators in plant disease resistance networks ${ }^{41}$. Global gene expression profiling has revealed a large number of WRKY genes rapidly induced or repressed upon pathogen infection, suggesting that WRKY genes may contribute to the regulation of responses to pathogen infection in rice ${ }^{22,42,43}$. Subsequent data analysis established that overexpression of $Z m W R K Y 65$, which was screened from the SA-induced de novo transcriptomic sequencing data of maize, could slow down the rate of wilting to enhance disease tolerance in Arabidopsis and increase the expression of disease-responsive genes (PR genes). In addition, many defense or defense-related genes, including well-studied PR genes and the regulatory NPR1 gene, contain in their promoters W-box elements that are specifically recognized by WRKY proteins and are necessary to induce the expression of those genes ${ }^{4-46}$. It has recently been reported that, by directly binding to the promoter of the defense-related gene OsPR10a, OsWRKY51 functions as a positive transcriptional regulator in defense signaling against $\mathrm{Xoo}^{25}$. Overexpression of PtrWRKY89 in transgenic poplar plants, which were more susceptible to both hemibiotrophic and necrotrophic pathogens, results in constitutive expression of PR genes ${ }^{47}$. AtWRKY70 was identified as a common regulatory component in SA- and JA-dependent defense-signaling pathways and mediates the cross-talk between these antagonistic pathways downstream of $N P R 1^{48}$. These results implied that WRKY transcription factors played an important role in disease resistance.

SA-mediated signaling pathways are important for disease resistance. The accumulation of SA can induce local defenses to stop pathogenic invasion and activate systemic acquired resistance ${ }^{7,49}$. Despite many studies reporting that SA-regulated gene transcript levels increase in Arabidopsis following the onset of disease, the use of SA biosynthetic and signaling mutants have not clearly revealed the roles of SA in Arabidopsis defense e $^{50}$. Experiments on transgenic plants have demonstrated various roles for SA in pathogen defense, such as basal defense to the fungal pathogen $B$. cinerea ${ }^{51}$. Our results showed that overexpression of $Z m W R K Y 65$ resulted in enhanced plant resistance to B. cinerea and Pst. DC3000 and improved expressions of SA-regulated PR genes, including PR1, PR2 and PR5 (Fig. 8B), these genes have been reported in enhancing the disease-resistant capacity of plants ${ }^{24,52-55}$. These results suggested that overexpression of $Z m W R K Y 65$ could promote the synthesis of SA, which resulted in the rapid accumulation of SA (Fig. 8C and Figure S4) and improved disease tolerance.

Many studies have revealed that WRKY genes are activated and up-regulated by drought, salt and exogenous hormones in a time-dependent manner, indicating that WRKY transcription factors are involved in the response to abiotic stress. In maize, the genes $Z m W R K Y 40$ and $Z m W R K Y 106$ were identified to enhance the tolerances to drought and high-temperature ${ }^{34,35}$. The protein structure analysis showed that there was the conservative amino acid sequence between $Z m W R K Y 65$ and $Z m W R K Y 106$ (Fig. 2B), and this result implied ZmWRKY65 may had the similar function in stress resistance with $Z m W R K Y 106$. To verify the roles of $Z m W R K Y 65$ in response to abiotic stress, transgenic Arabidopsis plants were exposed to drought, salt, high temperature and low temperature. Overexpression of $Z m W R K Y 65$ enhanced stress tolerance of the transgenic plants and the expression patterns of some stress-responsive genes such as $S T Z^{56,57}, E R D 10^{58}$ and $R D 29 A^{59}$ (Fig. $8 \mathrm{~B}, \mathrm{C}$ ). The accumulation of the plant hormone ABA is induced by drought, which contributes to stomatal closure and therefore prevents water $\operatorname{loss}^{60}$. Our results showed that transgenic plants displayed greater sensitivity to ABA than did WT plants when the leaves of both types of plants were treated with ABA; the ABA treatment resulted in rapid stomatal closure, possibly reducing water loss rates (Fig. 6) and improving drought tolerance. Hence, the ZmWRKY65 gene is likely an important component for abiotic and biotic signal transduction pathways and encodes a multifunctional factor that can integrate different stress signals in plants.

\section{Materials and methods}

De novo transcriptome sequence analysis of maize. Four-leaf stage maize inbred line B73 (From Chinese Academy of Agricultural Sciences, Beijing) seedlings grown under normal conditions $\left(25^{\circ} \mathrm{C} \pm 2{ }^{\circ} \mathrm{C}\right.$ temperature, $60-70 \%$ relative humidity, $18 \mathrm{~h}$ light $/ 6 \mathrm{~h}$ dark photoperiod, and natural sunlight) were washed off with water, and then the seedlings dehydrated on filter paper for $4 \mathrm{~h}$ and $5 \mathrm{mM} \mathrm{SA}$ for $4 \mathrm{~h}$ treatment, then the samples (each sample had the three repetitions) were collected for transcriptome sequence analysis ${ }^{61}$. Vertical bars indicate \pm SE of three replicates. The detailed process of transcriptome sequence analysis was exhibited as previous description.

Plant materials and stress treatments. Seeds of maize inbred line B73 were germinated in an incubator and then transferred to pots $(10-\mathrm{cm}$ diameter, 10 seedlings per pot) containing a vermiculite: soil mixture $(1: 1, \mathrm{v} / \mathrm{v})$. The seedlings were grown under the following conditions: $25^{\circ} \mathrm{C} \pm 2{ }^{\circ} \mathrm{C}$ temperature, $60-70 \%$ relative humidity, 18-h light/6-h dark photoperiod, and natural sunlight. For drought treatments, three-leaf-stage maize seedlings were dried and dehydrated on filter paper at $25^{\circ} \mathrm{C}$ and $20 \%$ relative humidity. For $\mathrm{NaCl}$ treatments, the seedling roots were immersed in $250 \mathrm{mM} \mathrm{NaCl}$. For hormone treatments, the leaves of maize seedlings were 
sprayed with different hormones (100 $\mu \mathrm{M}$ ABA and $5 \mathrm{mM} \mathrm{SA})$. After being treated, the seedlings were harvested at different time points, and the specific methods were described by Wang et al. $(2018)^{34}$.

RNA extraction and qRT-PCR. The maize tissue total RNAs were isolated by using the method was described by Yu et al. ${ }^{61}$, and first-strand cDNAs were synthesized using a PrimeScript First Strand cDNA Synthesis kit (TaKaRa, Japan). The cDNAs were combined with SYBR master mix (TIANGEN, China), and an ABI7300 system (Applied Biosystems, USA) was used to monitor the kinetics of the PCR products for qRT-PCR (consist of $94{ }^{\circ} \mathrm{C}$ for 3 minutes, and then 40 cycles of $94^{\circ} \mathrm{C}$ for $30 \mathrm{~s}, 60{ }^{\circ} \mathrm{C}$ for $15 \mathrm{~s}, 72^{\circ} \mathrm{C}$ for $34 \mathrm{~s}$ ). The maize actin gene (GRMZM2G126190) was used as an internal control for normalization of the template cDNA. The amount of accumulated transcript of the ZmWRKY65 gene normalized to the internal actin control gene was determined using the $2^{-\triangle \Delta C T}$ method. The qRT-PCR primers of $Z m W R K Y 65$ were provided in Table S2. Each sample PCR was repeated three to four biological replicates.

Gene isolation and sequence analysis. The ZmWRKY65 opening reading frames were obtained from the maize cDNA. The PCR products were cloned into pEASY-T1 vectors (TransGen) and then sequenced by using an ABI 3730XL 96-capillary DNA analyzer (Lifetech). Sequence alignment was performed by ClustalX using BioEdit software, and the sequences were adjusted manually. The neighbor-joining method was used to construct a phylogenetic tree by the MEGA5.1 program, and the confidence level of monophyletic groups was estimated using a bootstrap analysis of 1000 replicates $^{62}$.

Subcellular localization in protoplasts. For the subcellular localization analysis, the expression vector p16318GFP with a GFP tag was used. The methods about $Z m W R K Y 65$-hGFP recombinant vector construction were described by Yu et al. ${ }^{61}$, after which then transient expression vector ZmWRKY65-hGFP and the control vector p16318GFP were transformed into common wheat mesophyll protoplasts in accordance with the PEGmediated method ${ }^{63}$. After being cultured for $16 \mathrm{~h}$ in darkness, the wheat protoplasts were monitored by confocal microscopy to determine the subcellular localization of GFP expression. Specifically, GFP fluorescent signals were observed with a confocal laser scanning microscope (Nikon); FM4-64 dye (Molecular Probes, Carlsbad, CA) was excited at $543 \mathrm{~nm}$, and its fluorescence was recorded using a 650-nm long-pass filter.

Generation of transgenic Arabidopsis. The fragment of ZmWRKY65 was amplified and cloned into a modified pBI121 vector under control of the CaMV 35S promoter, resulting in a 35S::ZmWRKY65 construct. Arabidopsis thaliana ecotype Col-0 plants were grown under normal growth conditions $(16 \mathrm{~h}$ light/8 h dark photoperiod, $23{ }^{\circ} \mathrm{C}$ temperature, $60-70 \%$ relative humidity) until flowering. And we used the Agrobacturiummediated transformation method to generate the transgenic Arabidopsis lines ${ }^{61}$. The three T3 transgenic lines were chosen by semi-quantitative PCR for further analysis. The detection result was placed in Fig. 8A.

Performance of transgenic Arabidopsis under stress treatments. For the different hormone treatments, one hundred homozygous T3 transgenic lines and control plants seeds (which were subjected to 3 days of vernalization treatment) were placed on $1 / 2 \mathrm{MS}$ solid medium that were supplemented with different hormone treatments $(0.5 \mu \mathrm{M}$ ABA, $1 \mu \mathrm{M}$ ABA, $0.75 \mathrm{mM}$ SA and $1.5 \mathrm{mM} \mathrm{SA})$ for 4 days under normal conditions ( $16 \mathrm{~h}$ light $/ 8 \mathrm{~h}$ dark photoperiod, $23{ }^{\circ} \mathrm{C}$ temperature, $70 \%$ relative humidity); the germination rates were recorded during 4 days of treatment. Transgenic T3-generation Arabidopsis lines were used to perform stress tolerance assays. Three-week-old Arabidopsis plants grown in soil (including those subjected to 3 days of vernalization treatment) under normal conditions were stopped watering to expose to drought conditions for one week. After 7 days of drought treatment, the seedling plants were then re-watered and grow in the normal conditions for 7 days of recovery, and then the survival rates were recorded. For salt tolerance assays, 3-week-old Arabidopsis plants grown in soil under normal conditions were exposed to salt treatment (irrigation with $200 \mathrm{mM} \mathrm{NaCl}$ ); after 7 days of salt treatment, the survival rates were recorded. The experiments were repeated three times, and the results were consistent. One set of experiments is shown. For heat and cold tolerance assays, three-week-old Arabidopsis plants grown in soil under normal conditions were exposed to high temperature $\left(42^{\circ} \mathrm{C}\right)$ for $12 \mathrm{~h}$ and low temperature $\left(-8^{\circ} \mathrm{C}\right)$ for 3 days, and then the survival rates were recorded.

Tomato (Pst) DC3000 (virulent) fungal infection of transgenic plants. To explore transgenic plant disease resistance, four-week-old Arabidopsis plants were treated with B. cinerea conidiospores and Pseudomonas syringae pv. tabaci, respectively. The mock inoculations were carried out with sterile water and $10 \mathrm{mM} \mathrm{MgCl}$, respectively, and the details were described by Xu et al. ${ }^{17}$, Thilmony et al. ${ }^{65}$ and Lu et al. ${ }^{66}$.

The detection of SA content. Four-week-old seedlings of transgenic Arabidopsis and WT plants were treated with pathogens for 3 days, and then $0.5 \mathrm{~g}$ leaves with pathogens treatment and $10 \mathrm{mM} \mathrm{MgCl}_{2}$ treatment were harvested and ground to fine powder in liquid nitrogen, and then the samples was used for ELISA analysis. The methods of the ELISA assay were described by Lu et al. ${ }^{66}$.

Relative electrical conductivity. Sample leaves (0.1 g, 3-week-old Arabidopsis seedlings) of the transgenic and control lines (under natural growth conditions and subjected to stress treatments) were put into $10 \mathrm{~mL}$ of distilled water. To measure the initial electric conductance (S1) by FG3-B FiveGoTM conductivity meter (METTLER TOLEDO, Switzerland) $\left(25^{\circ} \mathrm{C}\right)$, a vacuum (test tube) was applied for $30 \mathrm{~min}$, after which the vacuum pressure surged for $2 \mathrm{~h}$. The applied temperature was then increased $\left(100^{\circ} \mathrm{C}\right)$ for $30 \mathrm{~min}$, after which it was 
reduced to room temperature $\left(25^{\circ} \mathrm{C}\right)$, at which point the final electric conductance (S2) was determined. The relative electrical conductivity was evaluated as $\mathrm{S} 1 \times 100 / \mathrm{S} 2$.

Analysis of stomatal aperture and water loss. Leaves of three-week-old Arabidopsis seedlings were collected and incubated for $4 \mathrm{~h}$ in stomatal-opening solution $\left(0.05 \mathrm{M} \mathrm{KNO}_{3}, 10 \mathrm{mM} 2\right.$-(N-morpholino) ethanesulfonic acid (MES), $\left.50 \mu \mathrm{M} \mathrm{CaCl}_{2}, \mathrm{pH}=6.15\right)$ under high-light conditions $\left(810 \mu \mathrm{mol} / \mathrm{m}^{2} / \mathrm{s}^{1}, 25^{\circ} \mathrm{C}\right)$, after which the leaves were transferred to an ABA-containing solution $(0,1 \mu \mathrm{M}$, and $15 \mu \mathrm{M})$ for $2 \mathrm{~h}$. The leaves were then mounted on slides and observed with a confocal laser scanning microscope (CLSM). To measure water loss, leaves of 3-week-old Arabidopsis plants were excised and placed on a bench $\left(25^{\circ} \mathrm{C}, 30 \%\right.$ relative humidity); the initial fresh weights of the leaves were measured at $0 \mathrm{~h}$ and recorded as $\mathrm{W} 0$, and then after $0.5 \mathrm{~h}, 2 \mathrm{~h}, 3 \mathrm{~h}$ and $5 \mathrm{~h}$, the fresh weights of leaves were measured and recorded as $\mathrm{Wn}(\mathrm{n}=0.5,2,3$, and 5$)$. The water loss rate was evaluated as: $(\mathrm{W} 0-\mathrm{Wn}) \times 100 / \mathrm{W} 0$.

\section{Data availability}

All the data supporting the findings is contained within the manuscript.

Received: 26 September 2019; Accepted: 27 January 2021

Published online: 17 February 2021

\section{References}

1. Xu, Z. S., Chen, M., Li, L. C. \& Ma, Y. Z. Functions of the ERF transcription factor family in plants. Botany. 86, 969-977 (2008).

2. Xu, Z. S., Chen, M., Li, L. C. \& Ma, Y. Z. Functions and application of the AP2/ERF transcription factor family in crop improvement. J. Integr. Plant Biol. 53, 570-585 (2011).

3. Peng, X. et al. OsWRKY80-OsWRKY4 module as a positive regulatory circuit in rice resistance against Rhizoctonia solani. Rice. 9, 63 (2016).

4. Asai, T. et al. Map kinase signalling cascade in Arabidopsis innate immunity. Nature 415, 977-983 (2002).

5. Jones, J. D. \& Dangl, J. L. The plant immune system. Nature 444, 323-329 (2006).

6. Tsuda, K., Sato, M., Stoddard, T., Glazebrook, J. \& Katagiri, F. Network properties of robust immunity in plants. Plos Genet. 5, 61-82 (2009).

7. Kunkel, B. N. \& Brooks, D. M. Cross talk between signaling pathways in pathogen defense. Curr. Opin. Plant Biol. 5, 325-331 (2002).

8. Kim, K. C., Fan, B. \& Chen, Z. Pathogen-induced Arabidopsis WRKY7 is a transcriptional repressor and enhances plant susceptibility to pseudomonas syringae. Plant Physiol. 142, 1180-1192 (2006).

9. Ricachenevsky, F. K., Sperotto, R. A., Menguer, P. K. \& Fett, J. P. Identification of fe-excess-induced genes in rice shoots reveals a WRKY transcription factor responsive to fe, drought and senescence. Mol. Biol. Rep. 37, 3735-3745 (2010).

10. Rushton, P. J. \& Somssich, I. E. Transcriptional control of plant genes responsive to pathogens. Curr. Opin. Plant Biol. 1, 311-315 (1998).

11. Eulgem, T., Rushton, P. J., Robatzek, S. \& Somssich, I. E. The WRKY superfamily of plant transcription factors. Trends Plant Sci. 5, 199-206 (2000).

12. Jiang, W., Wu, J., Zhang, Y., Yin, L. \& Lu, J. Isolation of a WRKY30 gene from muscadinia rotundifolia (michx) and validation of its function under biotic and abiotic stresses. Protoplasma. 252, 1-14 (2015).

13. Ulker, B. \& Somssich, I. E. WRKY transcription factors: from DNA binding towards biological function. Curr. Opin. Plant Biol. 7 , 491-498 (2004).

14. Dellagi, A., Heilbronn, J., Avrova, A.O., Montesano, M., Palva, E.T., \& Stewart, H.E., et al. A potato gene encoding a WRKY-like transcription factor is induced in interactions with erwinia carotovora subsp. atroseptica and phytophthora infestans and is coregulated with class i endochitinase expression. Mol. Plant Microbe Interact. 13, 1092-1101 (2000).

15. Lambais, M. R. In silico differential display of defense-related expressed sequence tags from sugarcane tissues infected with diazotrophic endophytes. Genet. Mol. Biol. 24, 103-111 (2001).

16. Liu, X., Bai, X., Wang, X. \& Chu, C. OsWRKY71, a rice transcription factor, is involved in rice defense response. J. Plant Physiol. 164, 969-979 (2007).

17. Xu, Z. S. et al. Isolation and molecular characterization of the Triticum aestivum L. ethylene-responsive factor 1 (TaERF1) that increases multiple stress tolerance. Plant Mol. Biol. 65, 719-732 (2007).

18. Ciolkowski, I., Wanke, D., Birkenbihl, R. P. \& Somssich, I. E. Studies on DNA-binding selectivity of WRKY transcription factors lend structural clues into WRKY-domain function. Plant Mol. Biol. 68, 81-92 (2008).

19. van Verk, M. C., Pappaioannou, D., Neeleman, L., Bol, J. F. \& Linthorst, H. J. A novel WRKY transcription factor is required for induction of PR1a gene expression by salicylic acid and bacterial elicitors. Plant Physiol. 146, 1983-1995 (2008).

20. Shen, H. et al. OsWRKY30 is activated by map kinases to confer drought tolerance in rice. Plant Mol. Biol. 80, 241-253 (2012).

21. Dong, J., Chen, C. \& Chen, Z. Expression profiles of the Arabidopsis WRKY gene superfamily during plant defense response. Plant Mol. Biol. 51, 21-37 (2003).

22. Ryu, H. S. et al. A comprehensive expression analysis of the WRKY, gene superfamily in rice plants during defense response. Plant Cell Rep. 25, 836-847 (2006).

23. Cheng, H. et al. The WRKY45, WRKY13, WRKY42 transcriptional regulatory cascade is required for rice resistance to fungal pathogen. Plant Physiol. 167, 1087-1099 (2015).

24. Choi, C. et al. Molecular characterization of Oryza sativa wrky6, which binds to w-box-like element 1 of the oryza sativa pathogenesis-related (PR) 10 a promoter and confers reduced susceptibility to pathogens. New Phytol. 208, 846-859 (2015).

25. Hwang, S. H. et al. OsWRKY51, a rice transcription factor, functions as a positive regulator in defense response against Xanthomonas oryzae pv. oryzae. Plant Cell Rep. 9, 1-11 (2016).

26. Wang, H. et al. Rice WRKY4 acts as a transcriptional activator mediating defense responses toward Rhizoctonia solani, the causing agent of rice sheath blight. Plant Mol. Biol. 89, 157-171 (2015).

27. Somssich, I. E. WRKY transcription factors: from DNA binding towards biological function. Curr. Opin. Plant Biol. 7, 491-498 (2004).

28. Andreasson, E. et al. The map kinase substrate mks1 is a regulator of plant defense responses. Embo J. 24, 2579-2589 (2005).

29. Qiu, J. L. et al. Arabidopsis map kinase 4 regulates gene expression through transcription factor release in the nucleus. Embo J. 27, 2214-2221 (2008).

30. Mao, G. et al. Phosphorylation of a WRKY transcription factor by two pathogen-responsive MAKPs drives phytoalexin biosynthesis in Arabidopsis. Plant Cell 23, 1639-1653 (2011). 
31. Yoo, S. J. et al. Involvement of the OsMKK4-OsMPK1 cascade and its downstream transcription factor OsWRKY53 in the wounding response in rice. Plant Pathol. J. 30, 168-177 (2014).

32. Ishihama, N., Yamada, R., Yoshioka, M., Katou, S. \& Yoshioka, H. Phosphorylation of the nicotiana benthamiana WRKY8 transcription factor by MAPK functions in the defense response. Plant Cell 23, 1153-1170 (2011).

33. Wei, K. F., Chen, J., Chen, Y. F., Wu, L. J. \& Xie, D. X. Molecular phylogenetic and expression analysis of the complete WRKY transcription factor family in maize. DNA Res. 19, 153-164 (2012).

34. Wang, C. T. et al. Maize WRKY transcription factor ZmWRKY106 confers drought and heat tolerance in transgenic plants. Int. J. Mol. Sci. 19, 3046 (2018).

35. Wang, C. T. et al. The maize WRKY transcription factor ZmWRKY40 confers drought resistance in transgenic Arabidopsis. Int. J. Mol. Sci. 19, 2580 (2018).

36. Singh, D. \& Laxmi, A. Transcriptional regulation of drought response: a tortuous network of transcriptional factors. Front. Plant Sci. 6, 895 (2015).

37. Bai, Y. L., Sunarti, S., Kissoudis, C., Visser, R. G. F. \& van der Linden, C. G. The role of tomato WRKY genes in plant responses to combined abiotic and biotic stresses. Front. Plant Sci. 9, 801 (2018).

38. Xiang, X. et al. Genome-wide identification and expression analysis of the WRKY gene family in common tobacco (Nicotiana tabacum L.). Hereditas. 38, 840-856 (2016).

39. Liu, Q. N. et al. Genome-wide identification and characterization of the WRKY gene family in potato (Solanum tuberosum). Biochem. Syst. Ecol. 71, 212-218 (2017).

40. Zhang, T., Tan, D. F., Zhang, L., Zhang, X. Y. \& Han, Z. X. Phylogenetic analysis and drought-responsive expression profiles of the WRKY transcription factor family in maize. Agric Gene. 3, 99-108 (2017).

41. Pandey, S. P. \& Somssich, I. E. The role of WRKY transcription factors in plant immunity. Plant Physiol. 150, 1648-1655 (2009).

42. Bagnaresi, P. et al. Comparative transcriptome profiling of the early response to, magnaporthe oryzae, in durable resistant, vs, susceptible rice (Oryza sativa, L.) genotypes. PLoS ONE 7, 5682-5700 (2012).

43. Wei, T. et al. Transcriptional profiling of rice early response to Magnaporthe oryzae identified OsWRKYs as important regulators in rice blast resistance. PLoS ONE 8, e59720 (2013).

44. Turck, F., Zhou, A. \& Somssich, I. E. Stimulus-dependent, promoter-specific binding of transcription factor WRKY1 to its native promoter and the defense-related gene pcpr1-1 in parsley. Plant Cell. 16, 2573-2585 (2004).

45. Yamamoto, S., Nakano, T., Suzuki, K. \& Shinshi, H. Elicitor-induced activation of transcription via w box-related cis-acting elements from a basic chitinase gene by WRKY transcription factors in tobacco . Biochim. Biophys. Acta (BBA) Gene Struct Expr. 1679, 279-287 (2004).

46. Lai, Z., Vinod, K., Zheng, Z., Fan, B. \& Chen, Z. Roles of Arabidopsis WRKY3 and WRKY4 transcription factors in plant responses to pathogens. BMC Plant Biol. 8, 68 (2008).

47. Jiang, Y. et al. Overexpression of poplar PtrWRKY89 in transgenic Arabidopsis leads to a reduction of disease resistance by regulating defense-related genes in salicylate- and jasmonate-dependent signaling. PLoS ONE 11, e0149137 (2016).

48. Li, J., Brader, G. \& Palva, E. T. The WRKY70 transcription factor: a node of convergence for jasmonate-mediated and salicylatemediated signals in plant defense. Plant Cell. 16, 319-331 (2004).

49. Fu, Z. Q. \& Dong, X. Systemic acquired resistance: turning local infection into global defense. Annu. Rev. Plant Biol. 64, 839-863 (2013).

50. Louis, J. \& Shah, J. Arabidopsis thaliana-Myzus persicae interaction: shaping the understanding of plant defense against phloemfeeding aphids. Front. Plant Sci. 4, 213 (2013).

51. Audenaert, K., De Meyer, G. B. \& Höfte, M. M. Abscisic acid determines basal susceptibility of tomato to Botrytis cinerea and suppresses salicylic acid-dependent signaling mechanisms. Plant Physiol. 128, 491-501 (2002).

52. Bari, R. \& Jones, J. D. G. Role of plant hormones in plant defense responses. Plant Mol. Biol. 69, 473-488 (2008).

53. Tateda, C. et al. Salicylic acid regulates Arabidopsis microbial pattern receptor kinase levels and signaling. Plant Cell 26, 4171-4187 (2014).

54. Canet, J. V., Dobon, A. \& Tornero, P. Non-recognition-of-BTH4, an Arabidopsis mediator subunit homolog, is necessary for development and response to salicylic acid. Plant Cell 24, 4220-4235 (2012).

55. Peng, X. et al. Constitutive expression of rice WRKY30 gene increases the endogenous jasmonic acid accumulation, PR gene expression and resistance to fungal pathogens in rice. Planta 236, 1485-1498 (2012).

56. Sakamoto, H., Araki, T., Meshi, T. \& Iwabuchi, M. Expression of a subset of the Arabidopsis Cys2/His2-type zinc-finger protein gene family under water stress. Gene 248, 23-32 (2000).

57. Sakamoto, H. et al. Arabidopsis Cys2/His2-type zinc-finger proteins function as transcription repressors under drought, cold, and high-salinity stress conditions. Plant Physiol. 136, 2734-2746 (2004).

58. Kiyosue, T., Yamaguchi-Shinozaki, K. \& Shinozaki, K. Characterization of two cDNAs (ERD10 and ERD14) corresponding to genes that respond rapidly to dehydration stress in Arabidopsis thaliana. Plant Cell Physiol. 35, 225-231 (1994).

59. Narusaka, Y. et al. Interaction between two cis-acting elements, ABRE and DRE, in ABA-dependent expression of Arabidopsis RD29A gene in response to dehydration and high-salinity stresses. Plant J. 34, 137-148 (2003).

60. Chandler, P. M. \& Robertson, M. Gene expression regulated by abscisic acid and its relation to stress tolerance. Annu. Rev. Plant Physiol. Plant Mol. Biol. 45, 113-141 (1994).

61. Yu, T. F. et al. Genome-wide analysis of the CDPK family in foxtail millet and determination of SiCDPK24 functions in drought stress. Front. Plant Sci. https://doi.org/10.3389/fpls.2018.00651 (2018).

62. Tamura, K. et al. MEGA5: molecular evolutionary genetics analysis using maximum likelihood, evolutionary distance, and maximum parsimony methods. Mol. Biol. Evol. 28, 2731-2739 (2011).

63. Liu, P. et al. A Arabidopsis PI4K gene whose product possesses threonine autophophorylation activity confers tolerance to drought and salt in Arabidopsis. J. Exp. Bot. 64, 2915-2927 (2013).

64. Berrocal-Lobo, M., Molina, A. \& Solano, R. Constitutive expression of ETHYLENE-RESPONSE-FACTOR1 in Arabidopsis confers resistance to several necrotrophic fungi. Plant J. 29, 23-32 (2002).

65. Thilmony, R. L., Chen, Z., Bressan, R. A. \& Martin, G. B. Expression of the tomato Pto gene in tobacco enhances resistance to Pseudomonas syringae pv tabaci expressing avrPto. Plant Cell. 7, 1529-1536 (1995).

66. Lu, P. P. et al. The wheat bax inhibitor-1 protein interacts with an aquaporin TaPIP1 and enhances disease resistance in Arabidopsis. Front Plant Sci. 9, 20 (2018).

\section{Acknowledgements}

We thank Mrs. Li-Na Ning so much for critically reading the manuscript.

\section{Author contributions}

C.T.W. coordinated the project and edited the manuscript; T.H. and T.F.Y. performed experiments and wrote the first draft; D.M.W., M.L. and D.Z. generated and analyzed data; Z.S.X., J.D.F., X.Y.S. and X.T.L. conceived and designed experiments, and edited the manuscript; all authors have read and approved the final manuscript. 


\section{Funding}

This study was financially supported by the National Transgenic Key Project of the Ministry of Agriculture of China (2018ZX0800909B), China Postdoctoral Science Foundation (2019M660886) and the Funding Project for Beijing Advanced Innovation Center for Food Nutrition and Human Health, and the Open Research Fund Program of Beijing Key Lab of Plant Resource Research and Development, Beijing Technology and Business University.

\section{Competing interests}

The authors declare no competing interests.

\section{Additional information}

Supplementary Information The online version contains supplementary material available at https://doi. org/10.1038/s41598-021-83440-5.

Correspondence and requests for materials should be addressed to J.-D.F., Z.-S.X. or X.-Y.S.

Reprints and permissions information is available at www.nature.com/reprints.

Publisher's note Springer Nature remains neutral with regard to jurisdictional claims in published maps and institutional affiliations.

(c) Open Access This article is licensed under a Creative Commons Attribution 4.0 International License, which permits use, sharing, adaptation, distribution and reproduction in any medium or format, as long as you give appropriate credit to the original author(s) and the source, provide a link to the Creative Commons licence, and indicate if changes were made. The images or other third party material in this article are included in the article's Creative Commons licence, unless indicated otherwise in a credit line to the material. If material is not included in the article's Creative Commons licence and your intended use is not permitted by statutory regulation or exceeds the permitted use, you will need to obtain permission directly from the copyright holder. To view a copy of this licence, visit http://creativecommons.org/licenses/by/4.0/.

(C) The Author(s) 2021 